\title{
The Role of Procedural Justice for Global Strategy and Subsidiary Initiatives
}

Geisler Asmussen, Christian; Foss, Nicolai J.; Nell, Phillip C.

\author{
Document Version \\ Accepted author manuscript \\ Published in: \\ Global Strategy Journal
}

DOI:

$10.1002 / g s j .1341$

Publication date:

2019

License

Unspecified

Citation for published version (APA):

Geisler Asmussen, C., Foss, N. J., \& Nell, P. C. (2019). The Role of Procedural Justice for Global Strategy and Subsidiary Initiatives. Global Strategy Journal, 9(4), 527-554. https://doi.org/10.1002/gsj.1341

Link to publication in CBS Research Portal

\section{General rights}

Copyright and moral rights for the publications made accessible in the public portal are retained by the authors and/or other copyright owners and it is a condition of accessing publications that users recognise and abide by the legal requirements associated with these rights.

\section{Take down policy}

If you believe that this document breaches copyright please contact us (research.lib@cbs.dk) providing details, and we will remove access to the work immediately and investigate your claim.

Download date: 26. Apr. 2023
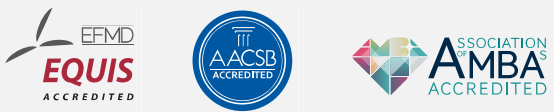


\section{The Role of Procedural Justice for Global Strategy and Subsidiary Initiatives}

\section{Christian Geisler Asmussen, Nicolai J. Foss, and Phillip C. Nell}

Journal article (Accepted manuscript*)

\section{Please cite this article as:}

Geisler Asmussen, С., Foss, N. J., \& Nell, P. C. (2019). The Role of Procedural Justice for Global Strategy and Subsidiary Initiatives. Globa/ Strategy Journal, 94), 527-554. https://doi.org/10.1002/gsj.1341

This is the peer reviewed version of the article, which has been published in final form at DOI: https://doi.org/10.1002/gsj.1341

This article may be used for non-commercial purposes in accordance with Wiley Terms and Conditions for Self-Archiving

* This version of the article has been accepted for publication and undergone full peer review but has not been through the copyediting, typesetting, pagination and proofreading process, which may lead to differences between this version and the publisher's final version AKA Version of Record. 


\title{
THE ROLE OF PROCEDURAL JUSTICE FOR
}

\section{GLOBAL STRATEGY AND SUBSIDIARY INITIATIVES}

\author{
Christian Geisler Asmussen \\ King's College London (King's Business School) \\ Franklin-Wilkins Building \\ 150 Stamford Street \\ London \\ United Kingdom \\ $\&$ \\ Department of Strategy and Innovation \\ Copenhagen Business School
}

Kilevej 14, 2nd floor; 2000 Frederiksberg; Denmark

cga.smg@cbs.dk; njf.smg@cbs.dk

Nicolai J. Foss

iCRIOS--Department of Management and Technology

Bocconi University

Via G Roentgen, 1; 20136 Milano; Italy

Phillip C. Nell

Institute for International Business

WU Vienna (Vienna University of Economics and Business)

Welthandelsplatz 1, D1 Building, 1020 Vienna, Austria, pnell@wu.ac.at

$\&$

Department of Strategy and Innovation

Copenhagen Business School

Kilevej 14, 2nd floor; 2000 Frederiksberg; Denmark

cga.smg@cbs.dk; njf.smg@cbs.dk

Keywords: Corporate headquarters, subunits, parenting, multi-business firms, procedural justice, anticipatory justice, psychological game theory, delegation, motivation.

Acknowledgments: We thank, without implicating, Laurence Capron, Raimondo CasadesusMasanel, Alfonso Gambardella, Jackson Nickerson, and Nils Stieglitz, and audiences at the Strategic Management Society, London Business School, Copenhagen Business School, and Bocconi University for comments on previous versions of this paper. 


\title{
THE ROLE OF PROCEDURAL JUSTICE FOR GLOBAL STRATEGY AND SUBSIDIARY INITIATIVES
}

\begin{abstract}
The global strategy literature highlights the role of headquarters (HQ) in realizing global integration benefits while enabling independent subsidiary strategic initiatives (MNCs). We construct a game theory model of the interaction between HQ and subsidiaries, and, building on procedural justice theory, we analyze the motivational costs that can result when HQ intervenes in subsidiary initiatives, aiming to realize global integration benefits. We also analyze the implications for MNC-level value creation when HQ managers, fearing subsidiary managers' emotion-based reactions, refrain from intervening. We derive a number of counterintuitive results, for example, that good HQ behavior may involve forgoing opportunities for value creation, and that procedural justice systems may sometimes be counterproductive.
\end{abstract}




\section{INTRODUCTION}

An important theme in global strategy is the role of subsidiaries' strategic initiatives (Birkinshaw \& Hood, 1998; Ambos, Andersson, \& Birkinshaw, 2010). Such "entrepreneurial proactive behavior in organizational subunits" (Strutzenberger \& Ambos, 2014: 314) may include developing a new product or process, and may contribute to corporate renewal and competitive advantage (Birkinshaw, 2000; Verbeke et al. 2007). Subsidiary initiatives thrive when subsidiaries benefit from autonomy (Birkinshaw, 1997). However, given its mandate to leverage international diversity (Ghoshal, 1987; Doz, Santos, \& Williamson, 2001) and to generate global integration benefits (Rugman \& Verbeke, 2001; Nohria \& Ghoshal, 1994), headquarters (HQ) ${ }^{1}$ may sometimes overrule subsidiary-level decisionmaking to fully leverage the global strategic potential of the local initiative (Birkinshaw, Hood \& Jonsson, 1998; Ambos \& Strutzenberger, 2013)—which we refer to as "HQ interventions" (Williamson, 1996; Foss, Foss \& Nell, 2012). Furthermore, while such interventions often seem valuable from a global strategy perspective, they also destroy value if entrepreneurially active subsidiary managers perceive the intervention as undue meddling, which may reduce subsidiary motivation (e.g. Mudambi, 2011; Foss et al., 2012). HQ therefore needs to adopt an approach to managing subsidiary initiatives that takes subsidiary motivation into account (Decreton, Nell, \& Stea, 2018). However, the current literature on subsidiary initiatives does not go sufficiently far here.

A case in point is the use of procedural justice in dealing with subsidiaries (cf. Kim \& Maubourgne, 1991, 1993; Luo, 2008; Johnson, Korsgaard \& Sapienza, 2002). Procedural justice refers to the fairness of procedures that govern decisions in organizations as perceived by those that are affected by the decision (Kim \& Mauborgne, 1991). Procedural justice may alleviate subsidiary

\footnotetext{
${ }^{1}$ By "HQ", we refer in this paper to global corporate top management, i.e. the set of executives that have global (non-area specific) responsibility (see Bouquet \& Birkinshaw, 2008) and their administrative support. However, our model is general enough to also apply to relationships between a regional HQ overseeing a smaller set of countries and its subsidiaries, in which similar issues may arise (see Verbeke \& Asmussen, 2016).
} 
motivation problems, while allowing HQ to intervene and to realize global integration benefits (Kim \& Mauborgne, 1991, 1995, 1996; Korsgaard et al., 2002). However, our understanding of the costs and benefits of procedural justice in MNCs is still highly incomplete. For example, complex and turbulent environments might make fair processes prohibitively costly, as they become very lengthy (Ellis et al., 2009), and there is little insight into the effect of varying levels of normative procedural justice expectations that subsidiary managers might have. Relatedly, we do not know much about the contingencies that shape initiative management and procedural justice. Is procedural justice equally valuable for MNCs that operate in a diverse set of host countries as for MNCs that operate in countries that are similar to each other? How does the importance of the subsidiary, or the attractiveness of the initiative project, influence the intervention dynamics?

Accordingly, the purpose of this article is to develop a precise understanding of the challenges of managing MNC subsidiaries in a procedurally just way, taking into account contingencies like the importance of the subsidiary and country diversity, as well as the dynamics between the HQ and subsidiaries. To handle this complexity, we build a game-theoretical model of HQ intervention during the subsidiary initiative process. We define an intervention as a decision by HQ to overrule the subsidiary's original choice of strategy for its initiative. Such an intervention allows the MNC to derive global economies of scale and scope, but it potentially demotivates subsidiary managers. Furthermore, we define also a mode of intervention. In our model, HQ can intervene either in a procedurally just way (i.e., one that follows fair procedures) or in an "authoritarian way" in which it exercises its formal authority without concern for procedural justice.

Our approach allows us to further the understanding of the interplay between the HQ and subsidiaries in the dynamic context of global strategy implementation. We make the following precise contributions to the global strategy, the subsidiary initiative, and the procedural justice literatures. First, 
we demonstrate that HQ opportunism and bounded rationality are not necessary conditions for "intervention hazards" to occur, as even rational and benevolent HQ intervention aimed at realizing global economies of scale and scope, can indeed harm motivation. This extends previous global strategy literature that has predominantly looked at ignorance and opportunism as reasons for the failure of MNC HQ activities (Ciabuschi et al., 2011). Second, we contribute to the parenting literature by showing that procedural justice can have not only positive but also, more surprisingly, negative effects on MNC

performance. We identify the contingencies delineating these opposing performance outcomes and show how key variables in our model, namely goal conflict between HQ and subsidiaries and the attractiveness of subsidiary initiatives, are based on three dimensions of interest to global strategy scholars: (1) the country diversity in the MNC network; (2) the importance of the subsidiary relative to the overall performance of the $\mathrm{MNC}$; and (3) the cost of undertaking the initiative, forging clear links to the broad global strategy literature.

\section{THEORETICAL BACKGROUND}

\section{Headquarters Intervention in the Subsidiary Initiative Process}

A key insight of the global strategy literature is that MNC HQ need to foster cross-border economies of scale and scope, while allowing for sufficient local responsiveness and initiative where necessary (Bartlett \& Ghoshal, 1989; Nell, Kappen \& Laamanen, 2017). Furthermore, a body of research examines subsidiary initiatives (starting with Birkinshaw, 1997), showing how initiatives may benefit the MNC at large, and that HQ should seek to manage subsidiaries in such a way that net gains from their initiatives are maximized. However, two key characteristics of the initiative process (cf. Mudambi \& Navarra, 2004) complicate this task.

The first is the semi-autonomous status of foreign subsidiaries. HQ typically delegates a set of decision rights to its subsidiaries, which enable the subsidiary to take entrepreneurial initiatives (e.g., 
Birkinshaw, 1997). However, delegation is never complete in the sense that the HQ retains some decision rights and can also overrule the decisions made by subsidiaries (i.e., intervene) (Baker, Gibbons \& Murphy, 1999). As a result, the HQ often faces a dilemma. For example, when US-based fast food chain Levendary Café expanded into China, HQ managers quickly found themselves torn between the promise of "free reins" given to the local manager to ensure swift growth in the turbulent Chinese restaurant market, and the need to intervene in order to safeguard the global brand and ensure restaurant system standards across countries (Bartlett \& Han, 2013). Hence, a difficult decision facing these HQ managers was whether or not to renege on earlier promises of autonomy made to the (overly) entrepreneurial manager of the Chinese market—or to entirely remove him from the position.

The second characteristic is a latent conflict of interests between the HQ and its subsidiaries. This is rooted in the interdependencies between the subsidiary and the rest of the MNC and in particular the effects of subsidiary initiatives on the other units managed by HQ. For example, positive spillovers (i.e., global integration benefits) from the subsidiary to the rest of the MNC occur when a subsidiary invests its resources into an innovative product-development initiative and the newly developed product can be profitably used in other MNC units (cf. Birkinshaw \& Hood, 1998; Asmussen, Foss, \& Pedersen, 2013). This is the ideal situation of dispersed corporate entrepreneurship in the MNC, which allows the firm to develop new markets, exploit their capabilities in new ways, and, ultimately, adapt to environmental change (Birkinshaw 1997, 2000; Frank, 2006; Doz, Santos, \& Williamson, 2001). However, this situation often does not develop naturally. For example, to enhance the appeal of the product to its own local consumers, the innovative subsidiary may revert to many localized features that make it more difficult for other units to use the product in their markets. Thus, the interest of the subsidiary (to maximize local profits) clashes in this moment with the interest of the HQ (to maximize global profits). 
These two characteristics of the initiative process matter for two reasons. First, they create a rationale for HQ intervention as HQ may want to intervene and overrule the subsidiary's initial decisions to generate global integration benefits. Second, they help explain why subsidiary managers may perceive such intervention negatively (i.e., as detrimental to their interests). This makes it crucial to investigate when and how HQs would intervene in subsidiary initiative processes. Yet, the current literature on subsidiary initiatives does not offer much insight into initiative management, including showing how it is shaped by contingencies like the importance of the subsidiary initiative or the country diversity of the MNC.

Of course, one possibility is that intervention occurs as a consequence of HQ managers suffering from bounded rationality, that is, making mistakes (Ciabuschi, Forsgren \& Martin, 2011; Kostova, Nell \& Hoenen, 2016) or acting on biases (Birkinshaw \& Ridderstrale, 1999). Previous studies mention notinvented-here syndromes and HQ managers' ignorance regarding what is going on and how to evaluate the interests of the subsidiary or the potential of the initiative (Ciabuschi et al., 2012). ${ }^{2}$ However, we focus on value-creating interventions only, and, hence, disregard HQ opportunism and bounded rationality. We do so for two reasons. First, we believe that many HQ interventions serve appropriate purposes, in the sense that $\mathrm{HQ}$ intervene to promote MNC performance. Second, we contribute with the insight that HQ opportunism and irrationality are not necessary conditions for intervention to be problematic: even interventions that seem entirely rational and benevolent terms in terms of increasing MNE profits may have demotivating effects on subsidiary managers (Mudambi, 2011). Nevertheless, our model is general enough to apply to scenarios of bounded rationality. An extension of our model that captures such scenarios is available from the authors upon request.

\section{HQ Intervention and the Role of Procedural Justice}

\footnotetext{
2 In this context, the notion of the "corporate immune system" has been used to refer to interventions from the corporate level as a largely over-reactive defense mechanism that inhibits MNC innovation (Birkinshaw \& Ridderstråle, 1999) and threatens initiative realization (Ambos \& Strutzenberger, 2013).
} 
To further our understanding of the role of $\mathrm{HQ}$, we also draw on the literature on procedural justice, that is, the perceived fairness of procedures that govern decisions in organizations (Kim \& Mauborgne, 1991, 1995, 1996; Korsgaard et al., 2002; Luo, 2005, 2008). ${ }^{3}$ This literature acknowledges that HQ decisions that clash with the interests of subsidiaries can be detrimental, but posits that rational, well-informed HQs will limit such consequences by applying just procedures, for example, accompanying decision-making with intensive bilateral communication between the HQ and the subsidiary, and letting subsidiaries challenge the HQ's views. Procedural justice enhances not only satisfaction with decision outcomes but also higher-order employee attitudes, such as trust (Folger \& Konovsky, 1998), compliance (Kim \& Mauborgne, 1991), and organizational-citizenship behavior (Kim \& Mauborgne, 1996). These outcomes emerge because employees who experience fair procedures feel respected, recognized, and valued (see Colquitt et al., 2001; Konovsky, 2000).

However, justice research in the global strategy literature rarely address the fact that procedural justice often involves lengthy and thus costly procedures (Ellis et al., 2009) and that it is implemented against a backdrop of subsidiary managers' normative expectations regarding fair procedures (Bicchieri $\&$ Chavez, 2010). There are MNCs with a strong procedural justice culture (one where subsidiary managers hold high normative justice expectations) and some where these expectations are generally weaker, and these differences should matter for HQ interventions and their consequences. Additionally, the procedural justice literature statically focuses on how individuals experience procedures (Rodell \& Colquitt, 2009). However, individuals also develop anticipations of justice ("anticipatory justice") prior to managerial intervention (Shapiro \& Kirkman, 1999). While ex post motivation levels are influenced by how individuals experience procedural justice when the decision is made, anticipatory justice might

\footnotetext{
${ }^{3}$ Procedural justice belongs to the broader literature on organizational justice, which also covers distributive justice and interpersonal justice (Colquitt, Conlon, Wesson, Porter \& Ng, 2001). We focus on procedural justice because it has been identified as one of the most important dimensions of justice (Colquitt et al., 2001), and because our subject of interest is the process of HQ intervention rather than exactly how individual employees are treated (interpersonal justice) or how specific decision outcomes differ among units (distributive justice).
} 
affect their ex ante motivation (the effort put into the initiative prior to the intervention). This suggests a subtle but important point: Managers' thinking about procedural justice can be conceptualized both in terms of expectations and anticipations. This has some largely unexplored motivational consequences that we address in terms of a game-theoretical model.

\section{A MODEL OF HEADQUARTERS-SUBSIDIARY INTERACTION}

We now model the dynamics of interaction between two players, namely a HQ and a representative subsidiary. The notion that subsidiaries are semi-autonomous is captured in our model by the HQ's option to intervene and overrule the subsidiary's strategy. As previously described, MNCs have to balance the forces of global integration (which may call for frequent HQ intervention) with those of local responsiveness (which favor delegating considerable autonomy to subsidiaries) in a context of geographical, national, and cultural diversity. This is what may cause a conflict of interest between the two players. The timing of the model is as follows:

1. The subsidiary decides whether to undertake a strategic initiative based on the decision rights granted to it (e.g., it may develop a new product for its local market).

2. The subsidiary chooses a "strategy" for the initiative. The initiative's strategy can either be "globally standardized" (GS) or "locally adapted" (LA). For example, the product may be designed using standardized MNC components (produced internally or procured from a supplier that supplies the whole MNC) or components that are locally sourced. ${ }^{4}$

3. The HQ decides whether to intervene by overruling the subsidiary's original choice, and changing the strategy of the initiative. If the HQ decides to intervene, it also chooses a mode of intervention, which will be either a procedurally just way (i.e., one that follows fair procedures) or an "authoritarian" way in which it exercises its formal authority without concern for procedural justice.

\footnotetext{
${ }^{4}$ In actuality, there is a continuum between globally standardized and locally adapted strategy. For the sake of simplicity, we make a distinction between the two extremes. The same holds for the two intervention extremes between authoritarian and fair procedures.
} 
4. The subsidiary chooses a "good citizen" or a "bad citizen" stance (LePine, Erez \& Johnson, 2002) and carries out the initiative with an effort level (i.e. motivation) that reflects this choice.

\section{Model Parameters}

The HQ's intervention decision is modeled by considering the performance implications of the strategic choice related to the initiative at both the subsidiary and MNC levels. We start by specifying the subsidiary's payoffs. The choice between the locally adapted strategy and the globally standardized strategy is a classic integration-responsiveness choice (Bartlett \& Ghoshal, 1989). For example, if the relevant initiative is the development of a new product, the locally adapted strategy may generate higher revenue in the local market, as the product would be better adapted to local tastes. However, the product may also be more costly to produce than it would be under the globally standardized strategy because the subsidiary cannot take advantage of MNC-wide economies of scale. For example, after Acer America designed Aspire for the US market, the company found that the cost of production was 10-15\% higher than for similar products because it did not use standard Acer parts (Bartlett \& St. George, 1998). Hence, we denote the subsidiary's payoff from undertaking the initiative as $\pi_{S U B}^{L A}$ if the locally adapted strategy is used, or $\pi_{S U B}^{G S}$ if the globally standardized strategy is used. We use the term initiative attractiveness to describe the extent to which one or both of these subsidiary payoffs are positive.

We assume that the HQ aims to maximize overall MNC performance, defined as $\pi_{M N C}=\pi_{S U B}+\pi_{R O M}$, where $\pi_{R O M}$ is the profits of the rest of the MNC as a consequence of the subsidiary initiative. As the MNC has full ownership of the subsidiary, the HQ's payoff consists of the sum of the focal subsidiary's payoffs $\left({ }^{\pi_{S U B}}\right)$ and the effect of the initiative and of the subsidiary's strategy in other MNC units $\left({ }^{\pi} R O M\right)$. We assume that the initiative, if implemented with a global strategy, confers a positive spillover of $\pi_{R O M}^{G S}>0$ onto the rest of the MNC due to economies of scale 
and scope enjoyed in other MNC units (Birkinshaw, 1997). However, if the initiative is performed with a locally adapted strategy, it results in lower spillovers to the rest of the MNC, $\pi_{R O M}^{L A}<\pi_{R O M}^{G S}$. The spillover from the locally adapted strategy is lower than the one from the globally standardized one due to a combination of foregoing some of the aforementioned economies of scale and scope (a loss of positive spillovers) and/or direct negative spillovers from the local strategy onto the MNC's brand and heightened risk exposure. ${ }^{5}$ This means that (disregarding the costs of intervention) the HQ will prefer the globally standardized strategy if $\pi_{M N C}^{G S}>\pi_{M N C}^{L A} \Leftrightarrow \pi_{R O M}^{G S}-\pi_{R O M}^{L A}>\pi_{S U B}^{L A}-\pi_{S U B}^{G S}$, in other words, if the higher spillover from the globally standardized strategy $\left(\pi_{R O M}^{G S}-\pi_{R O M}^{L A}\right)$ is not overwhelmed by higher subsidiary profits from the locally adapted strategy $\left(\pi_{S U B}^{L A}-\pi_{S U B}^{G S}\right)$.

With respect to intervention costs, we assume that a fair intervention process is associated with higher process costs than an authoritarian intervention process, as adhering to procedural justice principles consumes time and managerial resources (Ellis et al., 2009). ${ }^{6}$ For the sake of simplicity, we capture this contrast by assuming that the authoritarian intervention strategy has zero process costs, while the fair strategy that follows fair procedures has a cost of $g$. Hence, supposing that the globally standardized strategy is preferable from the HQ perspective, the MNE earns $\pi_{M N C}^{G S}$ if the subsidiary selects that strategy itself or if the HQ intervenes to achieve it in a procedurally unjust way. However, if the HQ intervenes using fair processes to achieve GS, it earns a lower payoff of $\pi_{M N C}^{G S}-g$. The costs of fair procedure, $g$, include the delays in the implementation of the initiative caused by extensive fair

\footnotetext{
${ }^{5}$ In addition to these direct effects of the locally adapted strategy, there could be indirect effects, for example if it diverted additional scarce subsidiary resources (e.g. managerial attention) away from other activities with more positive impact on the rest of the MNC. We do not distinguish between direct and indirect effects, since the consequences for HQ intervention are the same.

${ }^{6}$ By definition, fair processes involve both the HQ and the subunits. Therefore, costs of procedural justice occur on the HQ level and on the subunit level. For the sake of simplicity, we only model the costs of procedural justice for the HQ because we are ultimately interested in the intervention decision.
} 
procedures, which may mean that competitors beat the firm to the market or that political changes require adaptation of the initiative. Since a high pace of external change increases these risks, $g$ may be thought of as reflecting the degree of turbulence in the host country environment. Hence, our model captures the idea that fair processes can be prohibitively costly when turbulence is high (e.g., in emerging markets where first mover advantages are important and political instability creates institutional changes that might undermine current business models, or in high tech markets with short product life cycles). However, the cost of fair procedure might also reflect factors like cultural dissimilarity across nations and subsidiaries or a heterogeneous workforce.

Assumptions regarding the parameter space. In order to focus the analysis on relevant scenarios, we include two parameter restrictions. First, we assume that there is always goal conflict between the subsidiary and the headquarters. In the absence of goal conflict, the HQ would never have a reason to intervene in the subsidiary's choices, and the whole issue of fair versus authoritarian intervention, and the role of procedural justice, would be irrelevant. ${ }^{7}$ Concretely, we assume that the subsidiary always prefers local adaptation $\left(\pi_{S U B}^{L A}>\pi_{S U B}^{G S}\right.$ ), while the HQ always prefers global standardization ( $\pi_{M N C}^{G S}>\pi_{M N C}^{L A}$. This means that point (2) in the timing of the model becomes predetermined and that the subsidiary's first two choices can be reduced to one choice: take on the initiative with the locally adapted strategy or do not take on the initiative at all. We will use the difference $\left(\pi_{M N C}^{G S}-\pi_{M N C}^{L A}\right)$ as a way to quantify the extent of the HQ-subsidiary goal conflict, since this difference has important implications for the willingness of $\mathrm{HQ}$ to bear the direct and indirect costs of intervention.

Second, we assume that $\pi_{R O M}^{L A}>0$, that is, the negative spillover for the rest of the MNC of a subsidiary's decision to use the locally adapted strategy is no larger than the positive externality of the

\footnotetext{
${ }^{7}$ We thereby also exclude cases when there are no spillovers from the subsidiary project to the rest of the MNC, since that would imply the absence of goal conflict. Hence, the initiative has no implications for global strategy,
} 
overall initiative. This means that if the subsidiary would earn a non-negative payoff from the locally adapted strategy $\left(\pi_{S U B}^{L A}>0\right)$, then the HQ would also earn a non-negative payoff from that strategy ( $\pi_{M N C}^{L A}>0$; which is implied by the previous two inequalities) — although the HQ could intervene to gain a higher payoff because the globally standardized strategy is more attractive $\left(\pi_{M N C}^{G S}>\pi_{M N C}^{L A}\right)$. In this way, we intentionally limit the potential goal conflict between HQ and subsidiary, as the subsidiary's choices may be suboptimal but never totally unacceptable to the HQ. The most interesting and nuanced interactions occur in this gray zone of moderate goal conflict. ${ }^{8}$ After outlining the general results of our model, we will present a parameterization in which these two assumptions emerge naturally from the model.

\section{Procedural Justice}

In the final stage (4) of the model, we assume that subsidiaries adopt either a "good citizen" (LePine, Erez \& Johnson, 2002) stance in which they invest a high level of effort and make an honest attempt to succeed, or a "bad citizen" stance in which they shirk, cheat, or may even sabotage the initiative (cf. Vardi \& Weitz, 2004). This is costly to the MNC as bad citizenship implies exerting a lower level of effort, which implies a smaller chance that the subsidiary's product(s) will succeed and a worsened revenue/cost balance. A demotivated subsidiary engaging in bad citizenship behavior may also be less inclined to help other subsidiaries with, for example, transfer of practices, and may be less willing to absorb such practices from the HQ. This builds on the well-established link between experienced procedural justice and citizenship behavior (e.g., Moormann, Blakely \& Niehoff, 1998; Skarlicki and Folger, 1997). We normalize the payoff of the good citizen approach to zero and assume

\footnotetext{
${ }^{8}$ If we relax this assumption, certain combinations of the other parameters will lead to situations in which the HQ has an incentive to shut down the project entirely, requiring the addition of a fourth HQ strategy to our model. While this would not change our main conclusions in the sense that our propositions would still remain valid, the boundary conditions would become more complicated, adding unnecessary complexity to the model. In the interest of parsimony, therefore, we focus on situations in which incentives for intervention (defined as the overruling of strategies), rather than incentives for shutdown, exist. Results on this particular case are, however, available upon request to the authors.
} 
that the bad-citizen approach imposes an additional cost of $b_{S}$ on the subsidiary (and, thereby, on the HQ).

If subsidiaries were rational, both in terms of having standard economic preferences and in a subgame-perfect Nash equilibrium sense, the good citizen approach would always be chosen in the final stage. In other words, any threats to sabotage the initiative would not be credible because such actions would also diminish the payoff to the subsidiary itself. However, if subsidiary managers hold strong expectations of procedural justice, a different outcome is possible. To model this, we rely on the assumption of "Rabin fairness" (Rabin, 1993), that is, behaviors where individuals sacrifice part of their own material well-being to help (punish) other individuals who are being kind (unkind) to them. We assume that only the subsidiary managers are characterized by such preferences. ${ }^{9}$ This is asymmetric, as HQs are assumed to be "non-emotional," but this assumption is justified by our emphasis on subunit motivation and by the fact that it is the HQ that can overrule subsidiaries, not the other way around. In any case, when HQ intervene in an authoritarian way (e.g., because of time constraints), subsidiary managers will perceive the intervention as hostile because their justice expectations are not met. They will incur a psychological disutility, $\beta$, from this experience. However, they can eliminate this disutility if they subsequently pursue the bad-citizen approach because this allows them to punish the party they feel has been unfair to them and earn an equally high compensatory positive utility from doing so (Rabin, 1993; Fehr \& Gächter, 2000). ${ }^{10}$ Hence, we interpret $\beta$ as the strength of the normative procedural-justice expectations, which leads to a high disutility of being intervened upon in an authoritarian way, but also a high utility of punishing those that intervene.

\footnotetext{
${ }^{9}$ A more symmetric treatment would also substantially complicate the modeling effort.

${ }^{10}$ This is clearly a simplification, as one could also analyze cases in which the positive utility of bad citizenship is smaller or (perhaps somewhat perversely) larger than the negative disutility of intervention. However, this would introduce an additional parameter into the model without materially changing the insights it provides.
} 
Given these psychological aspects, a subsidiary that adopts the bad citizen approach following an authoritarian intervention will have a payoff of $-b_{S}$ (in addition to the payoffs resulting from the initiative itself), whereas the good-citizenship approach will result in a payoff of $-\beta$. The former will be chosen over the latter as long as $\beta>b_{S}$, which occurs whenever the fairness expectations are strong enough to compensate for the economic cost of the bad-citizen approach to the subsidiary manager. Of course, if the headquarters do not intervene or if they intervene fairly, the psychological payoffs $(\beta)$ do not come into play, and subsidiary managers will always choose the good-citizen approach.

\section{Results}

Analysis of the game tree allows us to identify the boundary conditions for the HQ intervention decision, which are important to establish at the outset because they interact with the effects of procedural justice expectations on subsidiary behavior. We describe the conditions formally in Appendix 1, but summarize the intuition here. For a fair intervention to occur there must be high procedural justice expectations, high goal conflict, and low costs of fair procedure. If just one of these conditions is not fulfilled, the HQ will not intervene with just procedures. Hence, if procedural justice expectations are low, HQ will intervene in an authoritarian way irrespective of the other parameters, as an authoritarian intervention is seemingly unproblematic for the HQ (subsidiary managers will be good citizens anyway). If goal conflict is low, the HQ will prefer to not intervene at all, because the benefits of doing so does not justify either the costs of fair procedures or the costs of bad citizenship. Finally, if the cost of fair procedure is high, one of two things can happen: HQ will intervene in an authoritarian way if goal conflict is high enough to justify the acceptance of the bad citizenship, and not intervene at all otherwise, since fair procedures are prohibitively costly and slow under turbulent conditions.

Committing to not being procedurally unjust. We noted above that authoritarian intervention is only "seemingly" unproblematic for the HQ when procedural justice expectations are low. This is because 
it has no negative performance consequences at the time when the decision is made. However, the mere anticipations of an intervention may have a negative effect on a subsidiary motivation to invest in an initiative in the first place, that is, before the decision is made (see also Baker et al., 1999). We illustrate this case with a numerical example in Figure 1.

\section{Insert Figure 1 here}

Consider a scenario in which an initiative is only marginally attractive to the subsidiary ( $\pi_{S U B}^{G S}-\beta<0<\pi_{S U B}^{L A}$ ), the external environment is turbulent (for example as in emerging markets characterized by institutional change and strong growth, which makes it very costly for the HQ to use

fair procedures $\left(g>b_{S}\right)$ ), and subsidiary managers hold low justice expectations $\left(\beta<b_{S}\right)$. The parameter values of this example are shown in Figure 1 (the underlying parameters $h, a, c$ will be introduced further below), as well as the payoffs resulting from those parameters in the two middle columns of the figure, with the bold payoff of -0.25 corresponding to low justice expectations (and the italicized payoff corresponding to a different scenario explained below).

To predict the outcome of this game, backwards induction is necessary. Hence, consider the subsidiary's citizenship decision in the last round. As $\beta<b_{S}$, the subsidiary's implicit threat of responding negatively to an authoritarian intervention is not credible and the subsidiary will choose the good citizen stance, as illustrated by the bold arrow marked $G C$. In anticipation of this, HQ will choose the authoritarian intervention if given the chance, shown with the bold arrow marked $A I$. Moving one stage backwards, the subsidiary will anticipate this intervention behavior and, accordingly, realize that the HQ will enforce the globally standardized strategy. As this outcome gives the subsidiary a negative economic payoff (-0.02) in addition to the psychological disutility of being overruled (an additional 0.2), it prefers not to undertake the initiative in the first stage. Hence, the subgame-perfect Nash equilibrium of this game has the subsidiary deciding to abandon the initiative before it even begins. 
Clearly, from the HQ perspective, this outcome is not optimal: the MNC foregoes profits of 1.18 because it cannot commit to constraining its own intervention behavior and because the subsidiary knows this. Hence, the $\mathrm{HQ}$, tempted to intervene in order to improve MNC performance by 0.28 , ends up losing 1.18 because the subsidiary managers anticipate the intervention and therefore prefer not to invest in the initiative. ${ }^{11}$ Thus, at low levels of justice expectations and moderate levels of initiative attractiveness, the HQ will face a commitment problem — being unable to credibly commit to either intervene with fair procedures or to not intervene at all—and the subsidiary managers will therefore pass on a valuable initiative because they expect authoritarian intervention. The subsidiary would have taken on the initiative if it had anticipated that the HQ would refrain from intervention $\left(0<\pi_{S U B}^{L A}\right)$. The subsidiary will not take on the initiative if it anticipates authoritarian intervention $\left(\pi_{S U B}^{G S}-\beta<0\right)$. Accordingly, the decision of whether to take on the initiative or not becomes contingent on this anticipation.

In sum, because the HQ cannot commit itself either to accepting the subsidiary's decision (even if intervening is for the common good of the MNC) or to using fair procedures (even though these entail unnecessary costs), the actions of subsidiary managers will be suboptimal (e.g., they will invest too little in initiatives that might benefit the MNC) for moderately attractive initiatives. This gives rise to a key question: Can increasing procedural justice expectations solve this problem, and if so, under which conditions? We now develop precise propositions that explain under which conditions increasing

\footnotetext{
${ }^{11}$ It may be argued that this problem can also be solved if the HQ compensates the subsidiary, e.g., by financing the fixed costs or by offering a (non-monetary) reward for undertaking the project. However, we refrain from analyzing this case for several reasons. First, it would assume that the HQ is aware of the project in the first stage when the subsidiary decides whether to initiate it. This assumption may not be realistic given the locally embedded nature of subsidiary initiatives (indeed, the identification of local projects could be seen as the raison-d'être of delegation). Second, subsidiary managers could present their project to the HQ and ask for financing, but this would likely be a costly and slow process that counters the idea of having entrepreneurial subsidiary managers who can quickly act on local opportunities. Third, compensating some subsidiaries may inspire others to ask for unnecessary compensation (for projects that they would undertake in any case), such that HQ would have an interest in committing to a no-compensation policy. Fourth, compensating subsidiaries essentially represents a redistribution of MNC funds, and compensating specific subsidiaries for some projects would inhibit the HQ's ability to allocate resources in a strategic manner (e.g., investing in high-growth markets in China).
} 
procedural justice expectations may enhance (Propositions 1), have no effect on (Propositions 2), or even harm (Propositions 3) the performance of the MNC. We describe the conditions formally in Appendix 2.

Solving the commitment problem: the role of procedural justice expectations. A way for MNCs to obtain HQ commitment is to influence the (normative) expectations of subsidiary managers. For example, Acer in the 1990s was characterized by a "long-established norm of delegation" operating under the slogan "every man is lord of his castle." This was part of a broader corporate culture reflecting the belief of founder and CEO Stan Shih that "major initiatives with global potential could be led from any part of the organization without centralized headquarters control" (Bartlett \& St. George, 1998: 1-2). A small change in the previous numerical example provides an indication of how this may work. Suppose procedural justice expectations are high in the MNC $(\beta=0.6)$ instead of low $(\beta=0.2)$. High justice expectations lead to high psychological disutility resulting from intervention and, in turn, it will be optimal for the subsidiary to "punish" the HQ to compensate for the experienced disutility, even if doing so leaves the subsidiary objectively worse off (as its economic payoffs are lowered by the badcitizen penalty).

This modified game is also shown in Figure 1 (with the dashed arrows and the italicized subsidiary payoff of -0.62 instead of -0.22 in the good citizen outcome). As seen in the figure, when the HQ intervenes in an authoritarian way, the subsidiary will internalize a positive psychological benefit (or, equivalently, avoid a negative psychological cost) of $\beta=0.6$ from harming the HQ by retaliating. This is now sufficient to compensate for the economic loss of $b_{S}=0.5$ and thereby makes the badcitizen behavior a credible threat. Realizing this, the HQ chooses not to intervene because the gain from changing the locally adapted strategy to a globally standardized one $\left(\pi_{M N C}^{G S}-\pi_{M N C}^{L A}=0.28\right)$ is smaller than the costs of the bad citizenship resulting from an authoritarian intervention $\left(b_{S}=0.5\right.$ ) and smaller 
than the procedural costs of a fair intervention $(g=0.6)$. The subsidiary, knowing that the expectation of its behavioral response will deter the HQ from intervention, expects to gain 0.05 and therefore undertakes the initiative in stage 1 . Hence, the motivation-destroying effect of anticipated intervention is subdued and the HQ can now obtain the second-best solution (resulting in 1.18). The general conditions for this to occur are captured in our Proposition 1:

Proposition 1: An increase in procedural justice expectations will solve the commitment problem in each of the following scenarios:

- 1A: When goal conflict is low, subsidiary managers will expect HQ to refrain from intervention and will therefore be motivated to undertake the initiative. ["Credible Delegation"]

- 1B: When goal conflict is high, initiative attractiveness is moderately high, and the cost of fair procedure is low, subsidiary managers will expect HQ to intervene with fair procedures and will therefore be motivated to undertake the initiative. ["Effective Justice"]

The Propositions 1A and 1B are consistent with much of the literature on the positive effects of procedural justice, and can be seen as providing a game-theoretic mechanism for some empirical regularities that have been observed in extant research.

The next propositions capture the scenarios in which higher justice expectations are insufficient to solve the problem:

Proposition 2: An increase in procedural justice expectations will not solve the commitment problem in each of the following scenarios:

- 2A: When goal conflict is high and the cost of fair procedure is high, subsidiary managers will expect HQ to intervene in an authoritarian way in spite of the ensuing bad citizenship behavior, and will therefore still pass on the initiative. ["Non-Credible Delegation"]

- 2B: When goal conflict is high, initiative attractiveness is moderately low, and the cost of fair procedure is low, subsidiary managers will expect $H Q$ to intervene using fair procedures, but this still will not be sufficient motivation to undertake the initiative. ["Ineffective Justice"]

In the scenarios under Proposition 1, increasing procedural justice expectations change the outcome of the game in a beneficial way, whereas under Proposition 2, the credible delegation problem remains. In the first case goal conflict must be lower than both the costs of bad citizenship and of fair procedure in 
order for intervention to be deterred entirely (1A). If the cost of fair procedure is high and the goal conflict is high relative to $b_{S}$, the HQ will still intervene in an authoritarian way, which will lead the subsidiary to pass on the initiative (2A).

If the cost of fair procedure is low and the goal conflict is high relative to $g$, the HQ will intervene fairly. The expectation of fair intervention, in turn, can have one of two consequences: at moderately high initiative attractiveness, it will be sufficient to motivate subsidiary managers (1B), while at moderately low attractiveness it will not (2B). For example, in Figure 1 even fair intervention will result in a negative payoff for the subsidiary $(-0.02)$ and, hence, will not be sufficient to solve the credible delegation problem.

\section{Detrimental effects of procedural justice expectations. Our findings so far show when} procedural justice expectations solve or do not solve the commitment problem. But, do these findings imply that high procedural justice expectations among subsidiary managers are generally preferable, in the sense that they at least are never harmful? Surprisingly, this is not the case: As soon as we move beyond the scenarios identified in Propositions 1 and 2 - in particular, when we deviate from the assumption of moderate initiative attractiveness - such expectations may become detrimental. To see this, consider another slight change in the numerical example depicted in Figure 2. Suppose that the initiative is highly attractive from the subsidiary perspective $\left(0<\pi_{S U B}^{G S}-\beta<\pi_{S U B}^{L A}\right)$ instead of just marginally attractive as in the previous example $\left(\pi_{S U B}^{G S}-\beta<0<\pi_{S U B}^{L A}\right)$. The games resulting from this change are illustrated in Figure 2 (low justice expectations: bold arrows and payoffs; high justice expectations: dashed arrows and italicized payoffs).

\section{------- Insert Figure 2}

A comparison of Figures 1 and 2 shows that the increase in initiative attractiveness does not change the HQ's intervention choice or the subsidiary's subsequent citizenship choice. Therefore, when procedural 
justice expectations are low, the HQ will still intervene and good citizen behavior will still be evident if the initiative is selected. However, the increase in initiative attractiveness changes the subsidiary's initial choice because the initiative becomes attractive even when intervention is anticipated. Therefore, even with low procedural justice expectations, the initiative is carried out, intervention occurs, and the MNC obtains the first-best outcome of 1.71 . However, when procedural justice expectations are high the threat of bad citizenship deters the HQ from intervening. As a result, the initiative is carried out using an inferior strategy, thereby lowering the profits of the MNC to 1.43 . Therefore, strong procedural justice expectations lead the HQ to forgo an opportunity for value creating intervention.

There are many scenarios in which MNC performance is lower when subsidiaries have high justice expectations as compared to the performance under low justice expectations. They all occur when the initiative is highly attractive to the subsidiary. These scenarios are captured in the following propositions:

Proposition 3: An increase in procedural justice expectations always has negative consequences at high levels of initiative attractiveness. These negative consequences take one of the following four forms:

- 3A: When goal conflict is low, high procedural justice expectations make any intervention prohibitively costly but do not increase the subsidiary managers' (already high) ex ante motivations, thereby leading the $H Q$ to forego an otherwise value-enhancing intervention. ["Forgone interventions"]

- 3B: When goal conflict is high and the cost of fair procedure is low, high procedural justice expectations lead the HQ to expend unnecessary resources and time on procedural justice in order to intervene fairly, but this has no positive effect on the subsidiary managers' (already high) ex ante motivations. ["Unnecessary procedures"]

- 3C: When goal conflict is high, the cost of fair procedure is high, and the initiative is highly attractive, high procedural justice expectations do not change subsidiary managers' ex ante motivations (as they take on the initiative in any case) or the behavior of the HQ (which intervenes in an authoritarian way in any case), but they do lead to bad-citizen behavior that would not have occurred given low procedural justice expectations. ["Disgruntled subsidiary managers"]

- 3D: When goal conflict is high, the cost of fair procedure is high, and the initiative is moderately highly attractive, high procedural justice expectations lead subsidiary managers to drop initiatives that they would otherwise have undertaken because they anticipate 
procedural justice expectations being violated by authoritarian intervention and their own ensuing bad-citizen behavior, which destroys the attractiveness of the initiative ["Forgone initiatives"].

In other words, when the initiative is highly attractive, strong procedural justice expectations lead the firm to incur the specific costs of "forgone interventions", "unnecessary procedures", "disgruntled subsidiary managers", or "forgone initiatives".

\section{THE EFFECT OF COUNTRY DIVERSITY AND SUBSIDIARY IMPORTANCE}

The overall conclusion from the previous section is that whether procedural justice expectations have a positive or negative impact on firm performance depends on the cost of fair procedure, goal conflict, and initiative attractiveness. To better understand these contingencies, in particular goal conflict and initiative attractiveness, we now analyze three antecedents: (1) the country diversity in the MNC network; (2) the relative importance of the subsidiary to the overall performance of the MNC; and (3) the cost of undertaking the initiative. These are important contingencies in the context of the international business literature. The discussion of the impact of country diversity on MNC performance has long been debated in international business research (e.g., Goerzen \& Beamish, 2003). Similarly, the relative "weight" of subsidiaries in the MNC has been the subject of a large research stream in the international business literature (e.g., Birkinshaw \& Hood, 1998; Rugman \& Verbeke, 2001; Mudambi \& Navarra, 2004). While there is little systematic knowledge of the costs of undertaking new subsidiary initiatives (Birkinshaw, 1997), extant examples of, for example, development of new markets (see Birkinshaw \& Fry, 1998) suggest that they can be substantial.

The context we will use for our analysis is one in which the subsidiary undertakes a new product development initiative based on a local opportunity — a type of subsidiary initiative often mentioned in the literature (Birkinshaw, 1997). A well-known example is the development of the Acer Aspire, which, was developed by Acer's US subsidiary in the 90 s based on the initiative of an entrepreneurial product 
manager in Silicon Valley (Bartlett \& St. George, 1998), and we will continue to refer to this example in explaining our setup in the following.

\section{Additional Model Parameters}

We assume that the new product development opportunity costs $c$ to pursue (e.g. in research and product development costs). Furthermore, when developing this product, the locally responsive subsidiary would like to choose product attributes to appeal to the preferences of its local customers. We capture this idea with a preference space scaled between 0 and 1, and assume that the subsidiary decides on a product attribute set denoted $s$, while preferences of the customers in the host market are given by an "ideal point" denoted $r_{S}$, within this space. The profit margin of the subsidiary is then given by $1-\left(r_{S}-s\right)^{2}$, implying that choosing $s=r_{S}$ results in profit margin of 1, while deviations from this ideal point makes the margin deteriorate at an increasing rate. Clearly, the locally responsive strategy is

to set $s=r_{S}$, and if the subsidiary had full autonomy this would be the expected outcome. In the case of Acer Aspire, the US managers were meticulous in their efforts to provide an accurate fit with consumer preferences, tapping into local design firms, arranging focus groups with customers, and interacting with retailers to uncover the drivers of US consumer behavior.

Of course, most subsidiaries are only semi-autonomous, and the ability of the MNE to orchestrate global innovation and apply subsidiary innovations outside of their originating markets can be seen as one of the advantages of multinationality. In the case of the Aspire, the product development team had direct support from Acer's headquarters in Taiwan, and there was a clear ambition of a global rollout of the innovative product after it was launched in the US. Yet, when the product was indeed launched, its success in other regional Acer markets was inhibited by the myriad differences between the primary US market (for which the Aspire was clearly designed) and these secondary markets in other regions. Often, the design decisions made by the US product managers were seen as 'inappropriate' 
when applied to other markets, leading to numerous costly modifications to the design and marketing of the product.

In our model, we capture this challenge with the possibility that customer preferences diverge between the markets of the focal subsidiary and those of the rest of the MNC, using $r_{M}$ to denote the preferences of the markets of the rest of MNC (which otherwise has a profit margin defined similarly to the subsidiary, i.e. $\left.1-\left(r_{M}-s\right)^{2}\right)$. To the extent that $r_{S}$ and $r_{M}$ differ, there is a goal conflict between the subsidiary and other units in the firm, and hence HQ has a potential reason to intervene in the product development of the subsidiary. The extent of this divergence, in turn, is expressed by the level of country diversity, $h \in[0,1]$, such that preferences are given by $r_{S}=\frac{1}{2}-\frac{1}{2} h$ and $r_{M}=\frac{1}{2}+\frac{1}{2} h$. Hence, when $h=0$, the ideal point of the subsidiary and the rest of the MNC coincides at $r_{S}=r_{M}=\frac{1}{2}$, while $h=1$ maximizes divergence such that $r_{S}=0$ and $r_{M}=1$. This assumption allows us to examine the impact of varying degrees of country diversity on the outcomes of our model by looking at the comparative statics of $h$.

The locally responsive strategy is given by $s=r_{S}=\frac{1}{2}-\frac{1}{2} h$, but what is the globally integrated strategy? Intuitively, since a benevolent MNC HQ will aim to maximize the performance of the entire MNC, including the innovative subsidiary and the rest of the firm, it will choose a product strategy that is somewhere in between the preferences faced by the subsidiary and the rest of the firm. In doing so, the relative weight it attaches to the focal subsidiary market and to the remaining markets in the MNC should depend on the relative importance of these markets to the overall MNC performance. For example, if the focal subsidiary is operating in the US market like in the Acer case, it is likely that it is quite important to overall MNC performance and that the MNC HQ would therefore prefer a product 
strategy that is not too far removed from preferences in that market. Conversely, if the subsidiary is in a small market (e.g., Austria) and the MNC has a large global footprint, it may attach less importance to those profits, and therefore be willing to enforce product strategies that are further removed from the local context of the subsidiary.

To capture this idea, we scale subsidiary profits by $1+a$ and rest of MNC profits by $1-a$, with $-1<a<1$. Hence, with $a=0$, the focal subsidiary carries the same weight as the rest of the MNC in the overall profit function, whereas the subsidiary becomes disproportionally small or large as a approaches -1 or 1 , respectively. With these assumptions, total MNC profits are given by:

$$
\pi_{M N E}=\pi_{S U B}+\pi_{R O M}=(1+a)\left(1-\left(\frac{1}{2}-\frac{1}{2} h-s\right)^{2}\right)+(1-a)\left(1-\left(\frac{1}{2}+\frac{1}{2} h-s\right)^{2}\right)
$$

The product strategy that maximizes this function can be shown to be $s=\frac{1}{2}-\frac{1}{2} a h$, which we therefore define as the globally integrated strategy. ${ }^{12}$ This strategy becomes increasingly distant from the locally responsive strategy (with higher $s$ ) as the subsidiary importance falls below 1 .

\section{Results}

In Appendix 3, we derive the predictions of the model based on the above assumptions. It can be shown that the two parameter constraints (goal conflict and non-negative spillovers) are always fulfilled. Figure 3 shows the HQ's intervention decision when justice expectations are high.

\section{Insert Figure 3 here}

\footnotetext{
12 Note that this is a weighted average of the subsidiary ideal point and the ideal point of the rest of the firm. With equal importance $(a=0)$, the optimum is the average of the two $\left(s=\frac{1}{2}\right)$; if all the weight is carried by the subsidiary $(a \rightarrow 1)$, the optimum coincides with the locally responsive strategy and the subsidiary's host country preferences $\left(s \rightarrow \frac{1}{2}-\frac{1}{2} h\right.$; and if the rest of the MNE has full weight $(a \rightarrow-1)$, the optimum $\left(s \rightarrow \frac{1}{2}+\frac{1}{2} h\right.$ ) coincides the preferences for the rest of the MNC.
} 
The impact of subsidiary importance. Clearly, subsidiary importance deters the HQ from intervening. When the subsidiary is large, goal conflict is low (because the MNC takes subsidiary interests into account in its calculus on the ideal global strategy) and the HQ is therefore likely to refrain from intervention. Conversely, when the subsidiary is less important, HQ will intervene, either with fair procedures if the cost of fair procedure is low enough to allow it, or in an authoritarian way if necessary. The subsidiary importance threshold at which intervention ceases depends on country diversity-if there is a large difference between the subsidiary and the rest of the MNC, goal conflict is high and therefore the HQ will intervene even in subsidiaries that are very important.

\section{------- Insert Figure 4 here --------}

Second, Figure 4 shows the boundary conditions of the moderate level of initiative attractiveness that cause commitment challenges to emerge and, in particular, how subsidiary initiative cost determines the calculations of the subsidiary managers. Intuitively, this variable determines the points at which the subsidiary managers will decide to undertake the initiative given varying anticipations of the HQ's intervention behavior. On the one hand, when initiative costs are very high $(c>1+a)$, nothing can convince the subsidiary managers to take on the initiative, which is unattractive even if they do not anticipate any HQ intervention. On the other hand, when initiative costs are very low ( $c<1+a-\frac{1}{4}(1-a)^{2}(1+a) h^{2}-\beta$ ), subsidiary managers will undertake it even if they anticipate authoritarian intervention, as they are willing to tolerate both the economic costs of having a global strategy imposed and the psychological disutility of being overruled. The commitment problem thus occurs only under moderate levels of initiative costs, where the subsidiary managers' incentives to take on the initiative depend on their anticipation of the HQ intervention choice, that is, on anticipatory procedural justice. When these costs are moderately high $\left(1+a-\frac{1}{4}(1-a)^{2}(1+a) h^{2}<c<1+a\right.$, 
initiative attractiveness is moderately low and the subsidiary will only take on the initiative if it anticipates no intervention - fair intervention is not enough, as it only removes the psychological disutility of intervention and not the subsidiary's economic loss associated with the initiative. On the other hand, when initiative costs are moderately low ( $\left.1+a-\frac{1}{4}(1-a)^{2}(1+a) h^{2}-\beta<c<1+a--\frac{1}{4}(1-a)^{2}(1+a) h^{2}\right)$, initiative attractiveness is moderately high and the subsidiary will take on the initiative if it anticipates either fair intervention or no intervention, and it will pass on the initiative only if it anticipates authoritarian intervention. Paradoxically, the latter choice means that the subsidiary leaves economic profits on the table because the initiative would be attractive to the subsidiary even with the HQ-enforced strategy. However, the anticipation of the psychological disutility of being overruled more than offsets those expected profits ( $\pi_{S U B}^{G S}-\beta<0 \Leftrightarrow \beta>\pi_{S U B}^{G S}$.

------- Insert Figure 5 here

Finally, building on both HQ intervention behavior and initiative attractiveness to the subsidiary, Figure 5 shows how the effects of strong procedural justice expectations, captured in Propositions 1-3, vary with the parameters of the model. The commitment problem occurs in the area between the two bold black lines, at intermediate levels of initiative attractiveness where the cost of the initiative is both low enough to make the local strategy worthwhile to the subsidiary and high enough to make intervention unacceptable. Whether high procedural justice expectations solve that problem, however, depends on the other parameters.

When country diversity is low enough (left of the vertical line), goal conflict is also low and therefore it is not worthwhile for HQ to intervene under high procedural justice expectations (which would lead it to incur costs of $\min \left(b_{S}, g\right)$. Subsidiary managers realize this and therefore undertake 
the project. If country diversity is high, on the other hand, HQ will still intervene under high procedural justice expectations - in an authoritarian way if the cost of fair procedure is high, and with fair procedures otherwise. ${ }^{13}$ In the former case, subsidiary managers always pass on the project and the problem is not solved. In the latter case, the expectation of fair intervention is sufficient motivation to take on the project when the initiative cost is below the dotted line, but not if it is above it.

Below the lowest bold line, the initiative cost is low enough for the subsidiary managers to take on the initiative irrespective of their expectations of HQ intervention (as long as they have low procedural justice expectations). If country diversity is low, an increase in procedural justice expectations then leads HQ to forgo a value-enhancing intervention, while if it is high, other types of negative consequences occur as a result of these expectations. Under low cost of fair procedure, HQ wastes resources on unnecessary fair procedure, and under high cost of fair procedure, HQ authoritarian intervention results in either bad citizenship behavior (below the dotted line) or dropped initiatives (above it). In all these cases, the MNC would have been better off without high procedural justice expectations, as described in Proposition 3.

Also, note that an increase in subsidiary importance (not shown in the figure) would have two effects: increasing initiative attractiveness and lowering goal conflict. This would make it less likely that the subsidiary managers will pass on the initiative, both because they get a higher payoff from the initiative even in the case of intervention, and because it is more likely that they will expect the headquarters to refrain from such intervention. This can be seen as motivation for the extensive innovation efforts undertaken by Acer's highly important US subsidiary: given the size and importance of the US market, the cost of the initiative was well worth it and it could be anticipated that Acer's

\footnotetext{
${ }^{13}$ The figure and the model is based on an assumption that country diversity and the cost of fair procedure are orthogonal. However, it country diversity leads to high cost of fair procedure (e.g. because of increased cultural barriers and misunderstandings), we would be more likely to get authoritarian intervention in distant subsidiaries, which would change our "effective fairness" scenario to one of "non-credible delegation".
} 
corporate HQ in Taiwan would not intervene in the development of the initiative - neither in an authoritarian way (due to the norms of delegation in the company) nor with fair procedures (due to the high turbulence in the consumer PC market leading to high cost of fair procedure) ${ }^{14}$ — which, in fact, they did not. This places the Acer Aspire case squarely within Proposition 3A (foregone interventions), with the subsequent barriers to the global roll-out of the product simply being the costs of HQ failing to provide intervention and control in the early stage of the development process, and illustrating how the culture of the company may have worked against it. In contrast, had the innovation occurred in a less important subsidiary, it would be more tempting for HQ managers to intervene and more likely that the anticipation of such intervention would deter the subsidiary managers from undertaking the project. In that case, high procedural justice could be beneficial, if it solved the commitment problem as described in Proposition 1 (credible delegation or effective justice). This means that a culture of procedural justice would be more suitable to implement in small subsidiaries than in large subsidiaries, as captured in the following proposition:

Proposition 4: When an increase in procedural justice expectations among managers in subsidiaries of low importance is beneficial to MNC performance (as described by $P 2$ ), and initiative costs are sufficiently low, a similar increase among managers in subsidiaries of high importance is detrimental to MNC performance (as described by P3).

The impact of country diversity. MNCs vary in terms of how diversified they are. Some MNCs focus on a set of highly related, similar countries. Other MNCs find themselves exposed to many, very diverse markets. Procedural justice expectations may play a different role in diverse vs. more homogenous MNCs. The grey arrow in the left panel of Figure 5 illustrates varying degrees of country diversity, and Figure 6 tracks the performance of MNCs along this arrow in the case of low (black line) and high justice expectations (bold gray line).

\footnotetext{
${ }^{14}$ For example, Bartlett and St. George (1998: 8) note that Acer could not afford the "unending negotiations" of global coordination in "a time-sensitive industry with rapid price fluctuations". Accordingly, the decision of Stan Shih to stay out of the US development process was motivated by his perception that time-to-market was crucial for the Aspire.
} 


\section{-------- Insert Figure 6 here --------}

At low levels of country diversity, procedural justice expectations are costly, because they prevent HQ from making a justified intervention in the subsidiary initiative (3A). At first, this does not cause much of a sacrifice in performance, but as heterogeneity increases, the costs of these expectations (the distance between the two lines) also increase, because the locally responsive strategy of the subsidiary moves away from what the HQ would have preferred from a global integration perspective. At some point, this cost becomes too high and the HQ instead prefers to intervene while expending resources on just procedures to avoid a negative subsidiary reaction (3B). In this area, the MNC incurs costs of justice expectations equal to $g$, so it would still be better for MNC performance if subsidiary managers did not have those expectations and would therefore accept an authoritarian intervention.

However, when diversity increases further, the commitment to these procedures suddenly becomes very important because now they are necessary to ensure that subsidiary managers undertake the initiative to begin with (2B). Finally, as country diversity becomes very high, the conflicts of interest between HQ and subsidiary managers escalate to the point where any investments into fair processes will not be enough to motivate the subsidiary initiative (3B): any intervention, even a fair one, is so costly to subsidiary managers that the anticipation of it will make them pass on the initiative.

In sum, our analysis implies that managers should not try to foster procedural justice expectations among their subsidiary managers at low levels of country diversity. However, at some point such expectations become a useful tool. However, it only works up to a limit, after which subsidiary initiatives are essentially stifled in the geographically overreaching MNC, irrespective of HQ intervention processes. We capture this in our final proposition:

Proposition 5: An increase in procedural justice expectations among subsidiary managers is detrimental to MNC performance at low levels of country diversity (as described by P3), beneficial at moderate levels of country diversity (as described by P1), and inconsequential at high levels of country diversity (as described by P2). 


\section{CONCLUDING DISCUSSION}

\section{Contributions to the Global Strategy Literature}

The global strategy literature often highlights the role of the HQ in realizing economies of scale, scope, and learning across the MNC network (e.g., Bartlett \& Ghoshal, 1989; Asmussen et al., 2013), while at the same time conceptualizing subsidiaries as units capable of independent, entrepreneurial initiative (Birkinshaw, 1997; Birkinshaw \& Hood, 1998). This article is taken up with rigorously analyzing the possible tensions that these two foci of extant global strategy research imply.

The literature has identifies two types of "facilitating conditions" for subsidiary initiatives: The first consist of the structural characteristics of the HQ-subsidiary relationship, such as subsidiary autonomy, resource position, and communication patterns, which might foster initiatives (Birkinshaw, 1997; Birkinshaw \& Fry, 1998). The second set focuses on HQ perspectives, suggesting in particular that HQ managers must overcome ingrained biases against subsidiary initiatives and develop a welcoming attitude towards them (Birkinshaw \& Fry, 1998, Birkinshaw \& Ridderstråle, 1999).

Our model extends such ideas by showing that the normative justice expectations of subsidiary managers can be important facilitating conditions for initiatives to take place. We have shown that such expectations are particularly useful when the international diversity of the MNC network is not too high and the importance of the subsidiary to the MNC is not too low, and the costs of subsidiary initiative are neither too high nor too low. ${ }^{15}$ Overall, we show that adverse motivational consequences can occur even if HQ interventions are based on unbiased evaluations (due to the interest conflict between HQ and subsidiaries), making the management of subsidiary perceptions and the creation of an appropriate culture of expectations throughout the organization a crucial task for MNCs. A key contribution of this article lies in the first precise identification of the conditions that determine HQ intervention modes (i.e.,

${ }^{15}$ In particular, if international diversity is high, goal conflict will be high and no amount of expectations can prevent intervention, whereas if initiative costs of anticipations are very low or very high, the anticipation of such intervention becomes inconsequential. 
no intervention, intervention with fair process, or intervention without fair processes) given precise assumptions about justice expectations, the cost of fair procedure, initiative attractiveness, and goal conflict.

Our results also have implications for the corporate HQ roles (e.g., Collis et al., 2007; Foss, 1997; Goold \& Campbell, 1998; Nell \& Ambos, 2013) and procedural justice literatures (Kim \& Maubourgne, 1991, 1993) in the context of the MNC. The former focuses on cases in which HQ activities create value for the firm. We show that even benevolent (i.e., not opportunistic) and wellinformed (i.e., not bounded rational) interventions may destroy value. As our main model does not assume biased estimates of the effects of intervention or opportunism by HQ managers (as in Ciabuschi et al., 2011), the damage to firm performance is driven solely by the effect of intervention on subsidiary incentives. We agree with the extant procedural justice literature that HQ may benefit from procedurally just decision making (Kim \& Mauborgne, 1991), and we identify the conditions under which this is the case (Proposition 1).

However, strong justice expectations are not a panacea, and there are situations where they are irrelevant (Proposition 2) or even harmful (Proposition 3). Hence, we conclude that procedural justice expectations can be both a boon and a bane to subsidiary initiatives: While these expectations can help the firm avoid inefficient intervention, their very existence implies that potential value creation will have to be sacrificed. This is a novel and subtle elaboration of Williamson's $(1985,1996)$ point that nonremediable inefficiencies are inherent to hierarchical organization.

Our findings also have implications for the procedural justice literature. In particular, we show the value of capturing procedural justice holistically by integrating not only experienced justice, but also normative justice expectations, justice anticipations, and also the costs of just procedures. All of these are areas that have received limited scholarly attention so far (Ellis et al., 2009; Franke et al., 2013). 
Our model enables us to make several new arguments. First, we argue that coming to grips with the functioning of procedural justice in the context of hierarchical relationships requires the modeling of procedural justice anticipations (cf. Rodell \& Colquitt, 2005). Second, we contribute by modeling subsidiary reactions in a way that integrates the psychological utilities that subsidiary managers may gain from punishing the intervening $\mathrm{HQ}$. We find that procedural justice in organizations can be beneficial not only because it directly influences the motivational disposition of subsidiary managersthe dominant reasoning in the literature, which essentially focuses on ex post motivation (e.g., Kim \& Mauborgne, 1996) — but also because it may deter HQ managers from intervening, thereby giving subsidiary managers stronger incentives to initiate new and profitable initiatives (higher ex-ante motivation). Third, we qualify the optimistic tenor of the procedural justice literature by identifying four types of potential costs of procedural justice: Forgone interventions, unnecessary procedures, and two distinct types of motivational costs, namely, post-intervention costs due to disgruntled subsidiary managers, and pre-intervention costs that emerge when subsidiary managers face incentives that make them refrain from investing into subsidiary initiatives. In particular, the costs of foregone intervention and missed initiatives are novel to the literature.

Finally, our study contributes to a better integration of economic and behavioral perspectives in the global strategy literature (Kostova, Nell \& Hoenen, 2016). Thus, in our model it is impossible to fully understand the performance implications of anticipations and expectations of procedural justice without simultaneously considering the attractiveness of the initiative from an economic perspective, because there is an interaction between the two dimensions. Thus, we find that the particularly interesting dilemmas relate to "borderline" attractive initiatives, which are only attractive to subsidiary managers if they anticipate a fair intervention, or no intervention. We believe this argument is new to the global 
strategy literature and that it demonstrates the importance of jointly considering economic and behavioral accounts of the motivations of subsidiary managers.

\section{Future Research}

While it is important to clarify the boundary conditions of procedural justice and to understand the nature of good HQ practices in MNCs, our research also has limitations. First, our propositions highlight the comparative statics of procedural justice expectations. However, our propositions and the model from which they are derived do not address the issue of how procedural justice expectations develop in the first place. Research shows that normative expectations are likely to develop gradually and informally as a result of repeated use and positive experiences linked to such norms. In other words, individuals' procedural justice preferences are shaped by past justice-relevant experiences (Bettenhausen \& Murnighan, 1985; Roberson \& Colquitt, 2005). For subsidiary managers, some of these justicerelevant experiences come from experiences outside the firm (in the case of new hires) or are determined by culture. However, past experiences with HQ interventions within the firm also serve as a major influence on justice expectations (Kreps et al., 1982). For example, the consistent application of fair procedures with positive effects for cooperation within the firm could lead to a gradual increase in employees' fairness expectations over time. This will make it more likely that they will react emotionally to the experienced fairness of HQ actions. As such, a self-reinforcing mechanism emerges (see Baker, Gibbons \& Murphy, 1999). Roberson and Colquitt (2005: 991) make very similar arguments with regards to the origins of anticipatory justice. Based on fairness heuristic theory, they submit that anticipated justice is driven by "global perceptions of fairness" that are "akin to a sort of justice reputation." Therefore, the frequent and consistent application of just procedures would also enable precise forecasts of such procedures by subsidiary mangers. Given the important effects of anticipatory justice and justice expectations, this calls for further research. 
Second, we have assumed that fair procedures are identified as such by HQ and subsidiary managers in a similar way. This is not necessarily true, as research has shown that both normative expectations and perceptions of justice may differ, and that the extent to which these perceptions are congruent has important implications (see Luo, 2005).

Third, as mentioned above, one of our assumptions has been that the HQ acts "rationally" in the sense that it accurately estimates the level of goal conflict and intervenes if this conflict outweighs the cost of intervention. This assumption might not be true ${ }^{16}$. However, our propositions do not depend on any assumption of a perfectly rational HQ as indeed it can be shown that minor deviations from rationality do not materially change the conclusions above. Nevertheless, deviations that are more substantial may moderate these conclusions by changing the predicted outcome between the different scenarios. We have analyzed both the role of "noise" (the HQ is inconsistent in its assessment of the performance effects of local vs. global strategies and, thus, of the level of goal conflict) and the role of systematic bias (e.g. the HQ systematically overestimates goal conflict). While the detailed results are available from the authors upon request, a few key insights can be mentioned here. In particular, noise can be a good thing for subsidiary initiatives when there is real goal conflict, as the uncertainty might lead the HQ to refrain from intervening in situations where it would otherwise have done so, and it can thereby alleviate the commitment problem that HQ faces. On the other hand, if there is no goal conflict in reality (so the locally adapted strategy is actually best for MNC performance), the uncertainty might then lead HQ managers to intervene erroneously and create new commitment problems where none existed before, and a similar outcome may occur if $\mathrm{HQ}$ is biased. This, in turn, creates a need for procedural justice, which can thus (also) be seen as a solution to commitment problems caused by uncertainty and biases. We encourage more work along these lines.

\section{Conclusion}

${ }^{16}$ We are grateful to one of the anonymous reviewers for raising the issues treated in this sub-section. 
Our theorizing and our model represent important steps towards the closer integration of key ideas on subsidiary initiative, HQ roles, and procedural justice in the broad global strategy literature. The overall, unique contribution of this article lies in the examination of the dynamics of the interaction between HQ and subsidiaries, which contributes to an improved understanding of the role of $\mathrm{HQ}$ in MNCs. In this regard, our model provides novel and non-intuitive insights into optimal HQ behavior and the way in which this is influenced by procedural justice anticipations and expectations.

\section{REFERENCES}

Aghion, P. \& Tirole, J. 1997. Formal and Real Authority in Organization. Journal of Political Economy, 105: 1-29.

Ambos, T., Andersson, U., \& Birkinshaw, J. 2010. What are the consequences of initiative-taking in multinational subsidiaries? Journal of International Business Studies, 41: 1099-1118.

Andersson, U., Forsgren, M., \& Holm, U. 2007. Balancing subsidiary influence in the federative MNC: A business network view. Journal of International Business Studies, 38(5), 802-818.

Asmussen, C. G., Foss, N. J., \& Pedersen, T. 2013. Knowledge Transfer and Accommodation Effects in Multinational Corporations: Evidence from European Subsidiaries. Journal of Management, 39(6), 1397-1429.

Baker, G., Gibbons, R., \& Murphy, K.J. 1999. Informal Authority in Organizations. Journal of Law, Economics \& Organization, 15: 56-73

Baron, J.N., \& Kreps, D.M. 1999. Strategic human resources: Frameworks for general managers. New York: Wiley.

Bartlett, C. A., \& St. George, A. 1998. Acer America: Development of the Aspire. Harvard Business School Case: 399011-PDF-ENG.

Bartlett, C. A., \& Ghoshal, S. 1989. Managing Across Borders. Boston: Harvard Business School Press. Battigalli, P. \& Dufwenberg, M. 2008. Dynamic psychological games. Journal of Economic Theory, 144, 1-35.

Bettenhausen, K., \& Murnighan, J. K. 1985. The emergence of norms in competitive decision-making groups. Administrative Science Quarterly, 350-372.

Bicchieri, C., \& Chavez, A. 2010. Behaving as expected: Public information and fairness norms. Journal of Behavioral Decision Making, 23: 161-178.

Birkinshaw, J. 1997. Entrepreneurship in multinational corporations: The characteristics of subsidiary initiatives. Strategic Management Journal, 18(3): 207-229. 
Birkinshaw, J. \& Fry, N. 1998. Subsidiary initiatives to develop new markets. Sloan Management Review, 39: 51-61.

Birkinshaw, J., \& Hood, N. 1998. Multinational subsidiary evolution: Capability and charter change in foreign-owned subsidiary companies. Academy of Management Review, 23(4): 773-795.

Bouquet, C., \& Birkinshaw, J. 2008. Weight versus voice: How foreign subsidiaries gain attention from corporate headquarters. Academy of Management Journal, 51(3): 577-601.

Birkinshaw, J., Hood, N., \& Jonsson, S. (1998). Building firm-specific advantages in multinational corporations: the role of subsidiary initiative. Strategic Management Journal, 19(3), 221-242.

Brockner J. 2002. Making sense of procedural fairness: how high procedural justice can reduce or heighten the influence of outcome favorability. Academy of Management Review, 27: 58-76.

Burks, S. V., \& Krupka, E. L. 2012. A multimethod approach to identifying norms and normative expectations within a corporate hierarchy: Evidence from the financial services industry. Management Science, 58: 203-217.

Campbell A, Goold M, \& Alexander M. 1995. Corporate strategy: the quest for parenting advantage. Harvard Business Review, 73: 120-132.

Carpenter, M. A. \& Golden, B. R. 1997. Perceived managerial discretion: A study of cause and effect. Strategic Management Journal, 18: 187-206.

Caza, A. 2012. Typology of the eight domains of discretion in organizations. Journal of Management Studies, 49: 144-177.

Ciabuschi, F., Forsgren, M., \& Martin M. 2011. Rationality vs. ignorance: The role of MNE headquarters in subsidiaries' innovation processes. Journal of International Business Studies, 42(7): 958-970.

Chalmers, J.M.R., L.Y. Dann, \& J. Harford. 2002. Managerial Opportunism? Evidence from Directors' and Officers' Insurance Purchases. Journal of Finance, 57: 609-636.

Chandler, A. D. 1991. The Functions of the HQ Unit in the Multibusiness Firm. Strategic Management Journal, 12: 31-50.

Collis, D., Young, D. \& Goold, M. 2007. The size, structure, and performance of corporate headquarters. Strategic Management Journal, 28: 383-405.

Colquitt J. A., Conlon D. E., Wesson M. J., Porter C. O. L. H., \& Ng K. Y. 2001. Justice at the millennium: a metaanalytic review of 25 years of organizational justice research. Journal of Applied Psychology, 86: 425-445.

Decreton, B., Nell, P. C., \& Stea, D. 2018. Headquarters involvement, socialization, and entrepreneurial behaviors in MNC subsidiaries. Long Range Planning.

Doz, Y. L., Santos, J., \& Williamson, P. 2001. From global to metanational: How companies win in the knowledge economy. Boston, MA: Harvard Business School Press.

Ellis, K. M., Reus, T. H. \& Lamon, B. T. 2009. The effects of procedural and informational justice in the integration of related acquisitions. Strategic Management Journal, 30: 137-161.

Fehr, E., \& Gächter, S. 2000. Fairness and retaliation: The economics of reciprocity. Journal of Economic Perspectives, 159-181. 
Folger, R. \& Konovsky, M.A. 1989. Effects of procedural and distributive justice on reactions to pay raise decisions. Academy of Management Journal, 32: 115-130.

Forsgren, M., Holm, U., \& Johanson, J. 1995. Division headquarters go abroad - a step in the internationalization of the multinational corporation. Journal of Management Studies, 32(4), 475491.

Foss, N. J. 1997. On the rationales of corporate headquarters. Industrial and Corporate Change, 6: 313338.

Foss, N. J. 2003. Selective intervention and internal hybrids: Interpreting and learning from the rise and decline of the Oticon spaghetti organization. Organization Science, 14(3), 331-349.

Foss, K., Foss, N. \& Nell, P. C. 2012. MNC organizational form and subsidiary motivation problems: Controlling intervention hazards in the network MNC. Journal of International Management, 18(3): 247-259.

Franke, N., Keinz, P., \& Klausberger, K. 2013. “Does This Sound Like a Fair Deal?”: Antecedents and Consequences of Fairness Expectations in the Individual's Decision to Participate in Firm Innovation. Organization Science, 24: 1495-1516.

Ghoshal, S. 1987. Global strategy: An organizing framework. Strategic Management Journal, 8(5), 425440.

Ghoshal, S., \& Bartlett, C. A. 1988. Creation, adoption, and diffusion of innovations by subsidiaries of multinational corporations. Journal of International Business Studies, 365-388.

Goerzen, A. \& Beamish, P. W. 2003. Geographic scope and multinational enterprise performance. Strategic Management Journal, 24: 1289-1306.

Goold, M. \& Campbell, A. 1998. Desperately seeking synergy. Harvard Business Review, 71: 131-143.

Goold, M., \& Campbell, A. 2002. Parenting in Complex Structures. Long Range Planning, 35: 219-243.

Johnson, J.P, Korsgaard, M.A. \& Sapienza, H.J. 2002. Perceived fairness, decision control, and commitment in international joint ventures management teams. Strategic Management Journal, 23: 1141-1160.

Kabanoff, B. 1991. Equity, equality, power, and conflict. Academy of Management Review, 16: 416-441.

Kim, W.C. \& Mauborgne, R.A. 1991. Implementing Global Strategies: The Role of Procedural Justice, Strategic Management Journal, 12:125-143.

Kim, W.C. \& Mauborgne, R.A. 1993. Procedural Justice, Attitudes, and Subsidiary Top Management Compliance with Multinationals' Corporate Strategic Decisions. Academy of Management Journal, 36: 502-526.

Kim, W.C. \& Mauborgne, R.A. 1995. A Procedural Justice Model of Strategic Decision Making: Strategy Content Implications in the Multinational. Organization Science, 6 (1): 44-61.

Kim, W. C. \& R. A. Mauborgne. 1996. Procedural justice and managers' in-role and extra-role behavior: The case of the multinational. Management Science: 499-515.

Korine, H. D. 1997. Managing innovation teams: A procedural justice perspective. Unpublished doctoral dissertation, INSEAD. 
Korsgaard, M.A., Sapienza, H.J. \& Schweiger, D.M. 2002. Beaten before begun: the role of procedural justice in planning change. Journal of Management, 28: 497-516.

Korsgaard M.A., Schweiger, D.M. \& Sapienza, H.J. 1995. Building commitment, attachment, and trust in strategic decision-making teams: the role of procedural justice. Academy of Management Journal, 38: 60-84.

Kostova, T., Nell, P. C., \& Hoenen, A. K. 2016. Understanding agency problems in headquarterssubsidiary relationships in multinational corporations: a contextualized model. Journal of Management.

Kreps, D. M., Milgrom, P., Roberts, J., \& Wilson, R. 1982. Rational cooperation in the finitely repeated prisoner's dilemma. Journal of Economic Theory, 27: 245-252.

LePine, J. A., Erez, A., \& Johnson, D. E. 2002. The nature and dimensionality of organizational citizenship behavior: A critical review and meta-analysis. Journal of Applied Psychology, 87: 5265 .

Li, H, Bingham, J.B. \& Umphress, E.E. 2007. Fairness from the top: perceived procedural justice and collaborative problem solving in new product development. Organization Science, 18(2): 200216.

Lind, E. A. \& T. R. Tyler. 1988. The Social Psychology of Procedural Justice. Plenum Press, New York.

Long C. P., Bendersky, C. \& Morrill, C. 2011. Fairness monitoring: Linking managerial controls and fairness judgments in organizations. Academy of Management Journal, 54(5): 1045-1068.

Lubatkin, M. H., Ling, Y. \& Schulze, W. S. 2007. An organizational justice-based view of self-control and agency costs in family firms. Journal of Management Studies, 44(6): 955-971.

Luo, Y. 2005. How important are shared perceptions of procedural justice in cooperative alliances. Academy of Management Journal, 48(4): 695-709.

Luo, Y. 2007. The independent and interactive roles of procedural, distributive, and interactional justice in strategic alliances. Academy of Management Journal, 50(3): 644-664.

Luo, Y. 2008. Procedural fairness and interfirm cooperation in strategic alliances. Strategic Management Journal, 29(1): 27-46.

Molm, L. D., Collett, J. L., \& Schaefer, D. R. 2007. Building solidarity through generalized exchange: A theory of reciprocity. American Journal of Sociology, 113: 205-242.

Moorman, R. H., Blakely, G. L., \& Niehoff, B. P. 1998. Does perceived organizational support mediate the relationship between procedural justice and organizational citizenship behavior? Academy of Management Journal, 41: 351-357.

Mudambi, R. 2011. Hierarchy, coordination, and innovation in the multinational enterprise. Global Strategy Journal, 1: 317-323.

Mudambi, R., \& Navarra, P. 2004. Is knowledge power? Knowledge flows, subsidiary power and rentseeking within MNCs. Journal of International Business Studies, 35(5): 385-406.

Nell, P. C. \& Ambos, B. 2013. Parenting advantage in the MNC: An embeddedness perspective on the value added by headquarters. Strategic Management Journal, 34: 1086-1103. 
Nell, P. C., Kappen, P., \& Laamanen, T. 2017. Reconceptualising hierarchies: The disaggregation and dispersion of headquarters in multinational corporations. Journal of Management Studies: 54(8), 1121-1143.

Nohria, N., \& Ghoshal, S. 1994. Differentiated fit and shared values: Alternatives for managing headquarters-subsidiary relations. Strategic Management Journal, 15(6), 491-502.

Rabin, M. 1993. Incorporating Fairness into Game Theory and Economics. American Economic Review, 83 (5): 1281-1302.

Roberson, Q. M. \& Colquitt, J. A. 2005. Shared and Configural Justice: A Social Network Model of Justice in Teams. Academy of Management Review, 30: 595-607.

Roberson, Q. M. \& Williamson, I. O. 2012. Justice in self-managing teams: the role of social networks in the emergence of procedural justice climates. Academy of Management Journal, 55(3): 685701.

Robinson, S. L. 1996. Trust and Breach of the Psychological Contract. Administrative Science Quarterly, 41: 574-599.

Rodell, J. B. \& Colquitt, J. A. 2009. Looking ahead in times of uncertainty: The role of anticipatory justice in an organizational change context. Journal of Applied Psychology, 94(4): 989-1002.

Rugman, A. M., \& Verbeke, A. 2001. Subsidiary-specific advantages in multinational enterprises. Strategic Management Journal, 22: 237-250.

Scott, B. A., Colquitt, J. A., \& Paddock, E. L. 2009. An actor-focused model of justice rule adherence and violation: The role of managerial motives and discretion. Journal of Applied Psychology, 94, 756.

Shapiro, D.L. \& Kirkman, B.L. 1999. Employees' reaction to the change to work teams: The influence of "anticipatory" injustice. Journal of Organizational Change Management, 12(1): 52-66.

Shapiro, D.L. \& Kirkman, B.L. 2001. Anticipatory injustice: The consequences of expecting injustice in the workplace. Greenberg J \& Cropanzano R, eds. Advances in Organizational Justice. Stanford University Press, Stanford, CA: 152-178.

Tekleab, A. G., Takeuchi, R., \& Taylor, M. S. 2005. Extending the chain of relationships among organizational justice, social exchange, and employee reactions: The role of contract violations. Academy of Management Journal, 48(1), 146-157.

Thibaut J. \& Walker L. 1975. Procedural justice: A Psychological Analysis. Erlbaum: Hillsdale, NJ.

Skarlicki, D. P., \& Folger, R. 1997. Retaliation in the workplace: The roles of distributive, procedural, and interactional justice. Journal of Applied Psychology, 82(3), 434.

Vardi, Y., \& Weitz, E. 2004. Misbehavior in organizations: Theory, research, and management. Mahwah, NJ: Lawrence Erlbaum.

Verbeke, A., \& Asmussen, C.G. 2016. Global, local, or regional? The locus of MNE strategies. Journal of Management Studies, 53 (6): 1051-1075.

Williamson, O.E. 1985. The Economic Institutions of Capitalism. New York: Free Press

Williamson, O.E. 1996. The Institutions of Governance. Oxford: Oxford University Press. 
FIGURE 1

Procedural justice expectations enabling credible delegation (P1A)

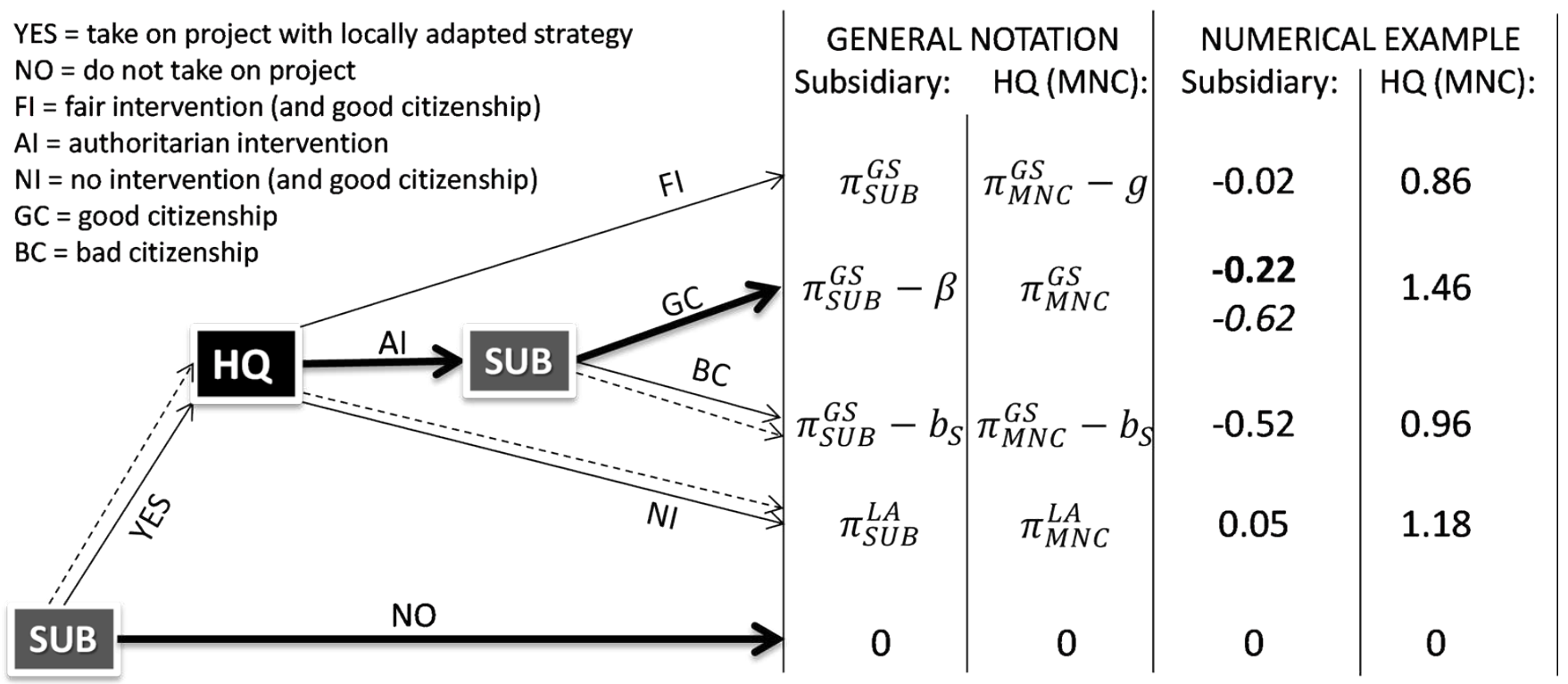

Parameter Values: $g=0.6, b_{S}=0.5, h=0.5, a=-0.5, c=0.45$

Low PJ Expectations (Bold Arrows): $\beta=0.2$

High PJ Expectations (Dashed Arrows): $\beta=0.6$ 
FIGURE 2

Procedural justice expectations leading to foregone interventions (P4A)

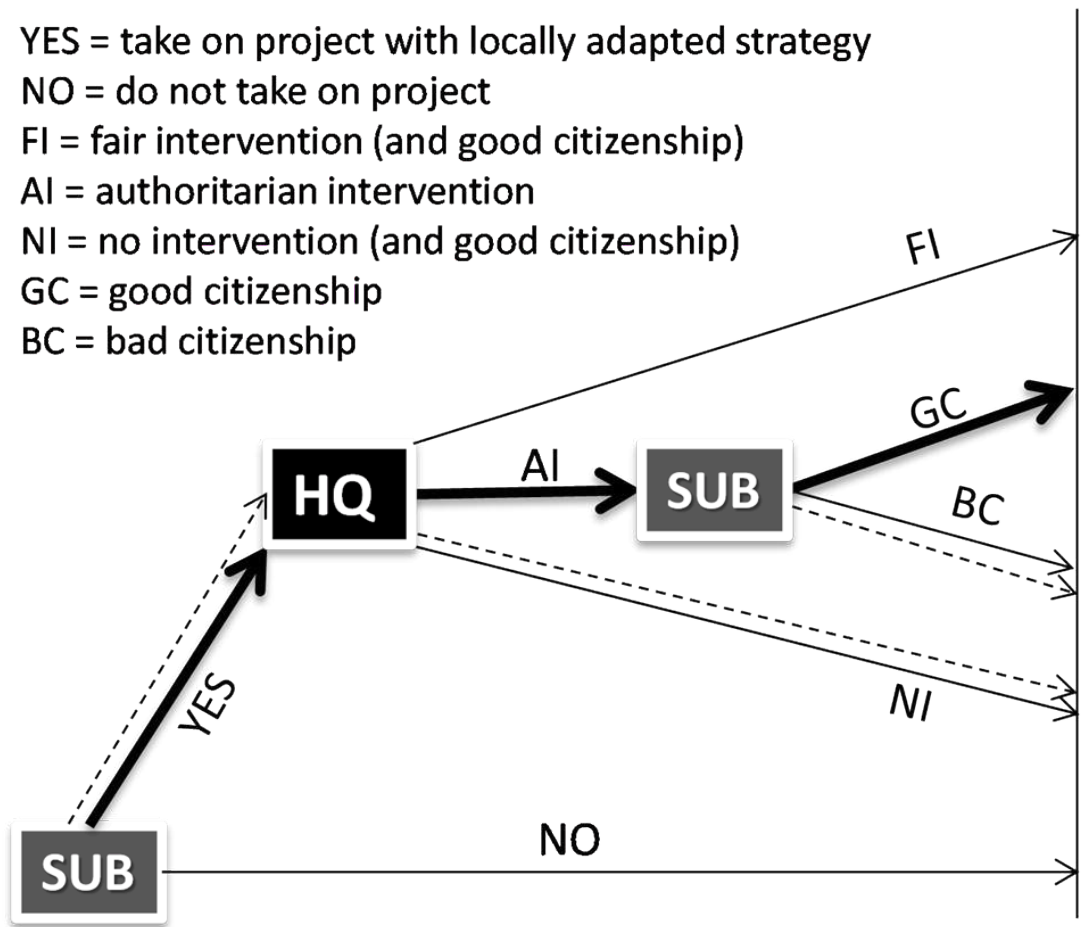

\begin{tabular}{c|c|}
\multicolumn{2}{c|}{ PAYOFFS } \\
Subsidiary: & HQ (MNC): \\
0.23 & 1.11 \\
0.03 & 1.71 \\
-0.37 & \\
-0.07 & 1.41 \\
0.30 & 1.43 \\
0 & 0
\end{tabular}

Parameter Values: $g=0.6, b_{S}=0.3, h=0.5, a=-0.5, c=0.2$

Low PJ Expectations (Bold Arrows): $\beta=0.2$

High PJ Expectations (Dashed Arrows): $\beta=0.6$ 
FIGURE 3

The HQ intervention decision under high procedural justice expectations
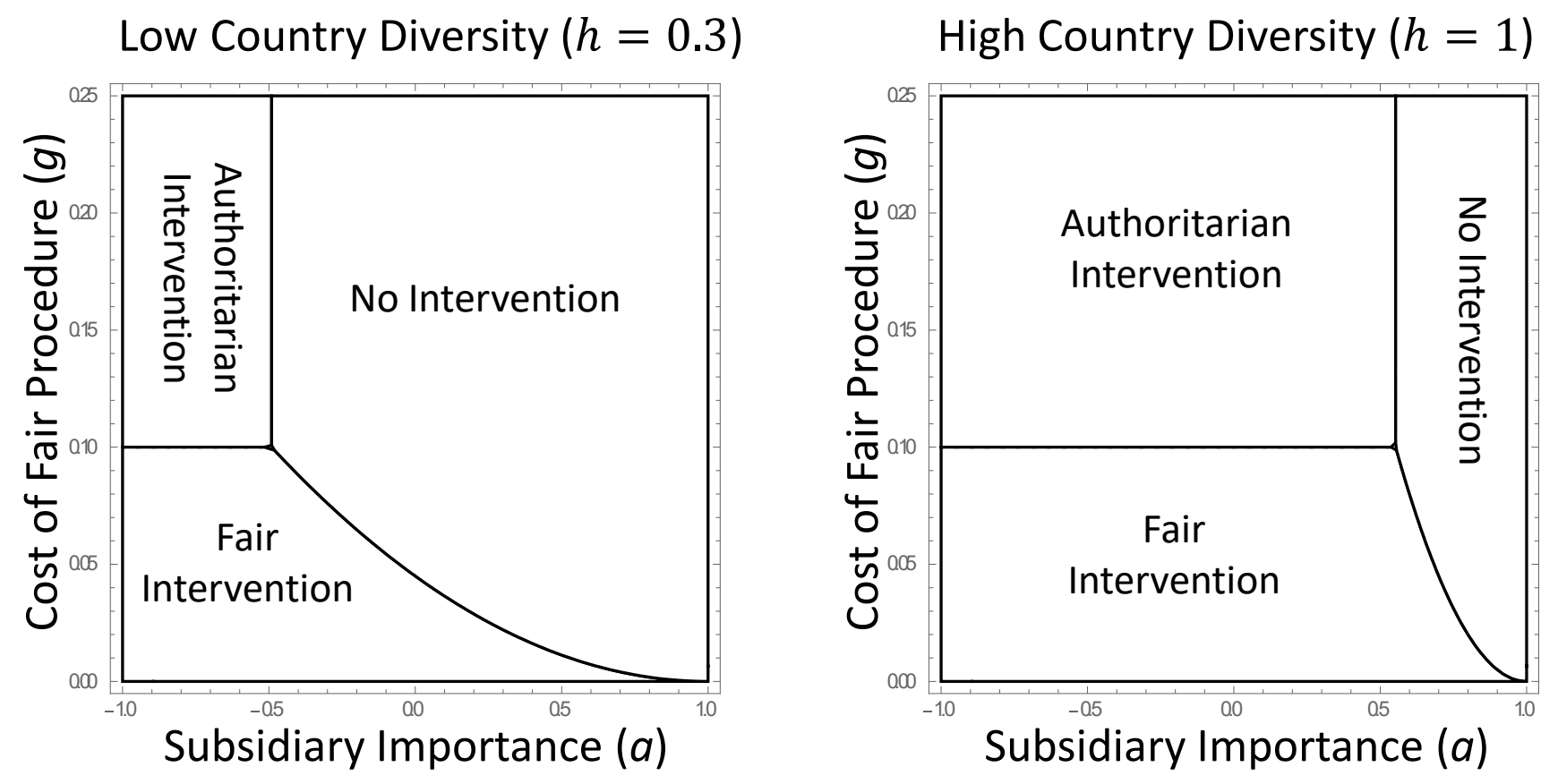
FIGURE 4

Initiative cost, initiative attractiveness, and credible delegation

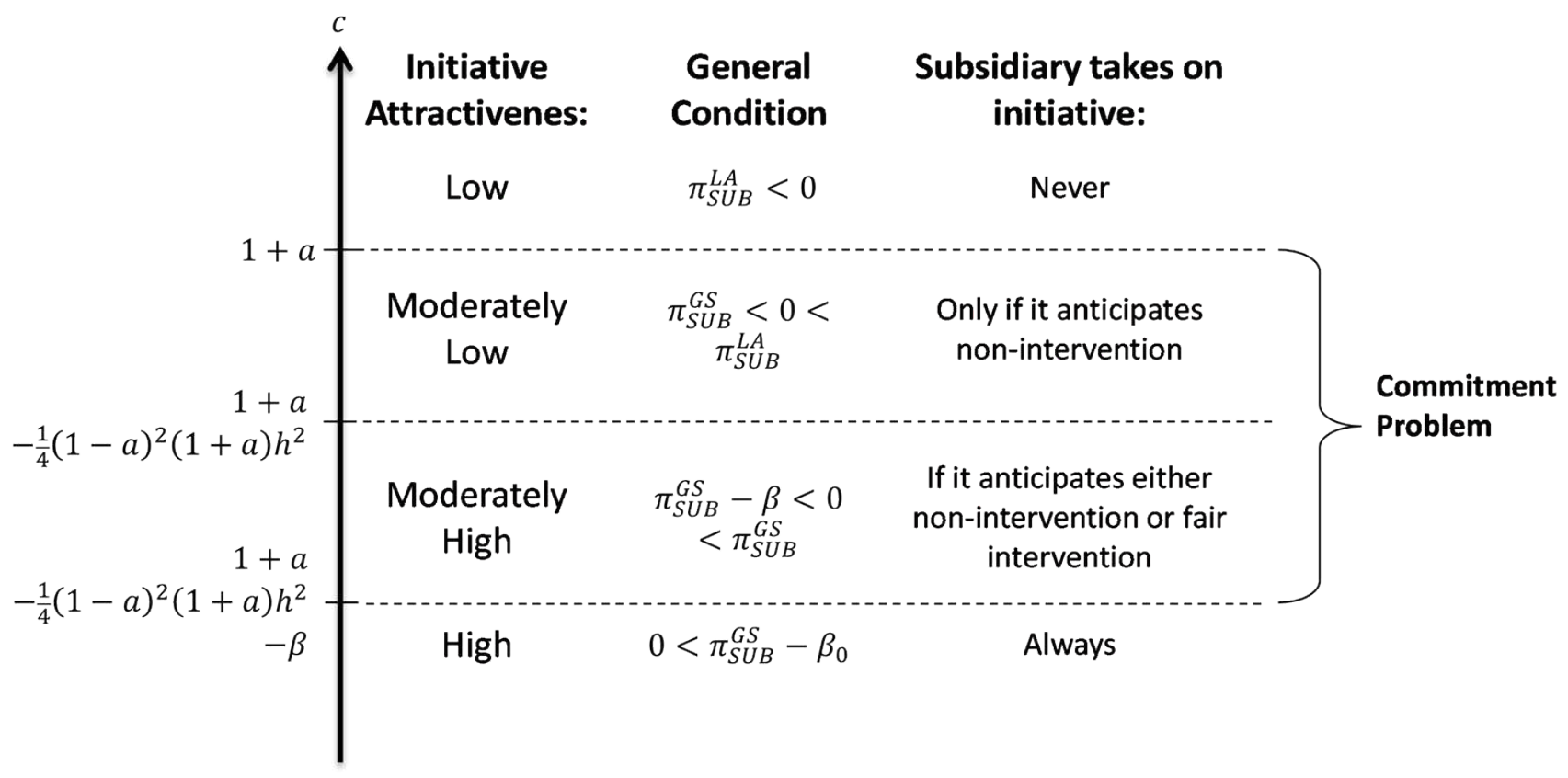


FIGURE 5

Comparative statics under high procedural justice expectations: Country diversity, initiative cost, and the cost of fair procedure
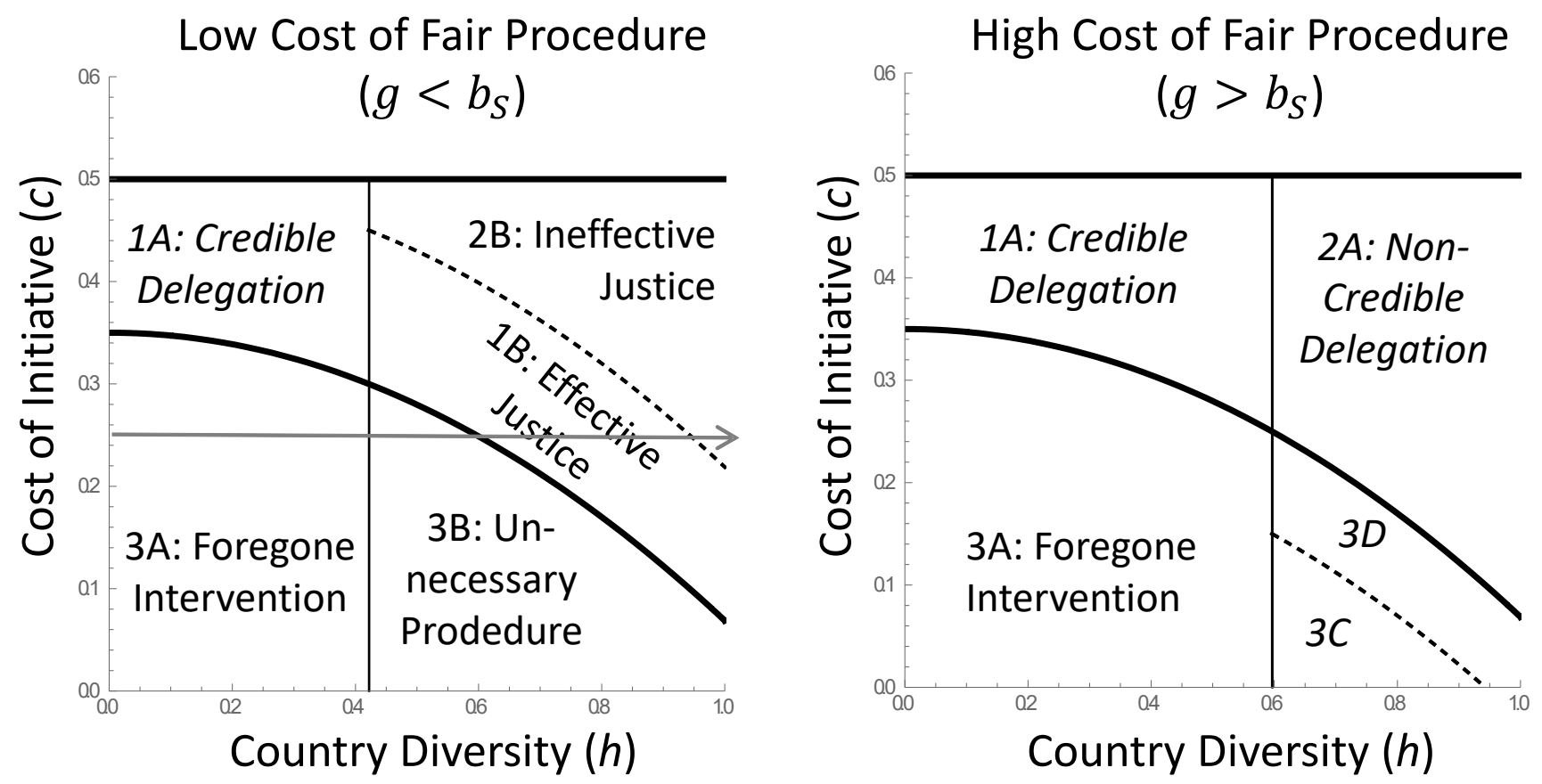
FIGURE 6

The interactive effect of country diversity and procedural justice expectations

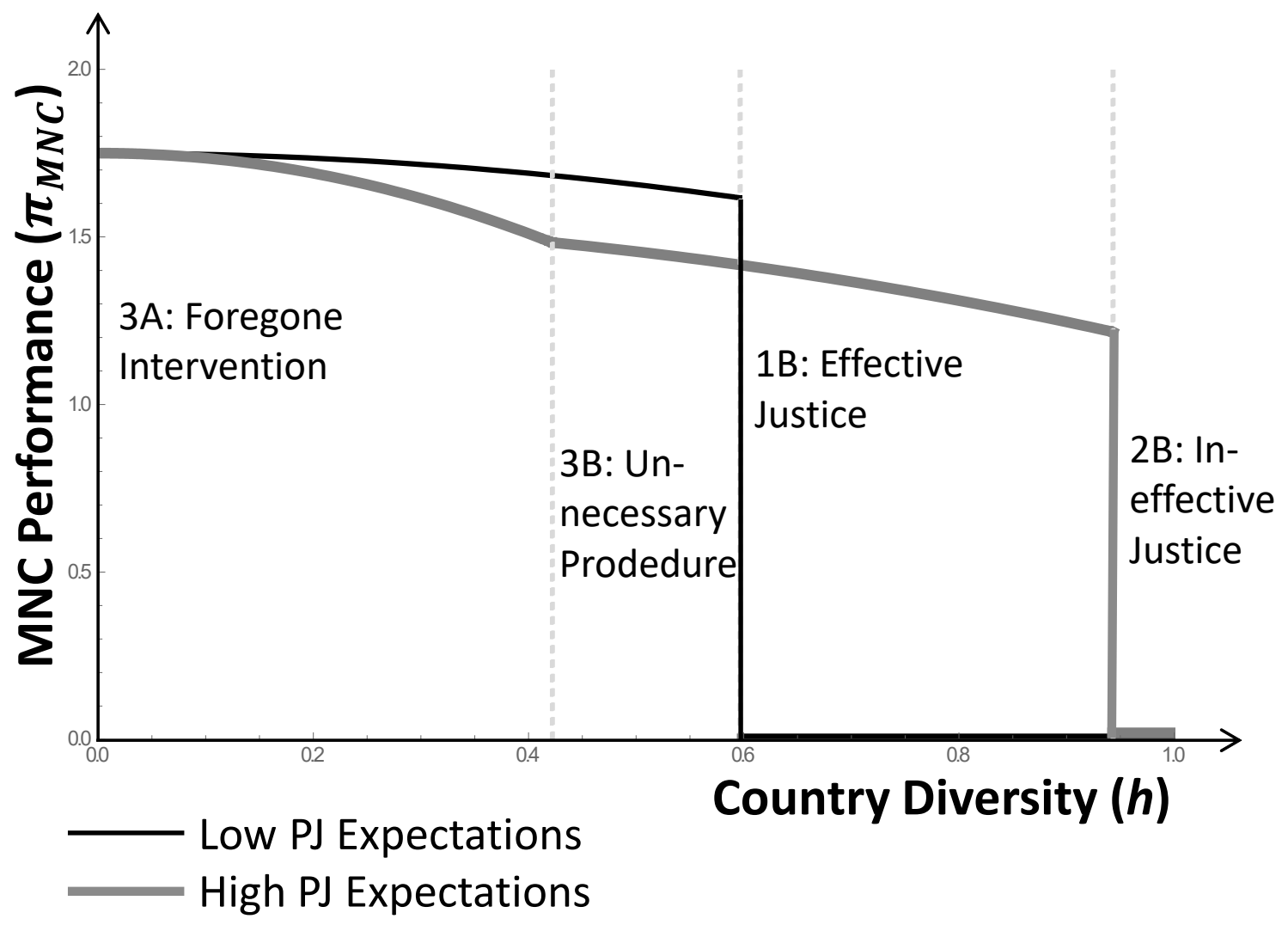




\section{APPENDIX 1}

Formal conditions for HQ intervention decisions: The HQ will intervene using procedural-justice principles when there are high procedural-justice expectations $\left(\beta>b_{S}\right)$ as well as relatively high goal conflict $\left(\pi_{M N C}^{G S}-\pi_{M N C}^{L A}>g\right)$ and low cost of fair procedure $\left(g<b_{S}\right)$.

The HQ will not intervene when there are high procedural-justice expectations $\left(\beta>b_{S}\right)$ combined with low goal conflict $\left(\pi_{M N C}^{G S}-\pi_{M N C}^{L A}<\min :\left(b_{S}, g\right)\right.$ ).

The HQ will intervene in an authoritarian way when one (or both) of the following two scenarios occurs:

- There are low procedural-justice expectations $\left.\beta<b_{S}\right)$, or

- High goal conflict $\left(\pi_{M N C}^{G S}-\pi_{M N C}^{L A}>b_{S}\right)$ and high cost of fair procedure $\left(g>b_{S}\right)$ are simultaneously present.

\section{APPENDIX 2}

Formal propositions:

Proposition 1: An increase in procedural justice expectations from $\beta_{0}<b_{S}$ to $\beta_{1}>b_{S}$ will solve the commitment problem in each of the following scenarios:

- 1A: When goal conflict is low $\left(\pi_{M N C}^{G S}-\pi_{M N C}^{L A}<\min \omega\left(b_{S}, g\right)\right)$, subsidiary managers will expect $H Q$ to refrain from intervention and will therefore be motivated to undertake the initiative. ["Credible Delegation"]

- 1B: When goal conflict is high $\left(\pi_{M N C}^{G S}-\pi_{M N C}^{L A}>g\right)$, initiative attractiveness is moderately high $\left(\pi_{S U B}^{G S}-\beta<0<\pi_{S U B}^{G S}<\pi_{S U B}^{L A}\right)$, and the cost of fair procedure is low $\left(g<b_{S}\right)$, subsidiary managers will expect $H Q$ to intervene with fair procedures and will therefore be motivated to undertake the initiative. ["Effective Justice"]

Proposition 2: An increase in procedural justice expectations from $\beta_{0}<b_{S}$ to $\beta_{1}>b_{S}$ will not solve the commitment problem described in Proposition 1 in each of the following scenarios:

- 2A: When goal conflict is high $\left(\pi_{M N C}^{G S}-\pi_{M N C}^{L A}>b_{S}\right)$ and the cost of fair procedure is high( $g>b_{S}$ ), subsidiary managers will expect $H Q$ to intervene in an authoritarian way in spite of the ensuing bad citizenship behavior, and will therefore still pass on the initiative. ["NonCredible Delegation"].

- 2B: When goal conflict is high $\left(\pi_{M N C}^{G S}-\pi_{M N C}^{L A}>g\right)$, initiative attractiveness is moderately low $\left(\pi_{S U B}^{G S}-\beta<\pi_{S U B}^{G S}<0<\pi_{S U B}^{L A}\right)$, and the cost of fair procedure is low $\left(g<b_{S}\right)$, subsidiary 
managers will expect HQ to intervene using fair procedures, but this still will not be sufficient motivation to undertake the initiative. ["Ineffective Justice"]

Proposition 3: All else equal, an increase in procedural justice expectations from $\beta_{0}<b_{S}$ to $\beta_{1}>b_{S}$ always has negative consequences at high levels of initiative attractiveness $\left(0<\pi_{S U B}^{G S}-\beta_{0}<\pi_{S U B}^{L A}\right)$. These negative consequences take one of the following four forms:

- 3A: When goal conflict is low $\left(\pi_{M N C}^{G S}-\pi_{M N C}^{L A}<\min \left[\left(b_{S}, g\right)\right.\right.$, high procedural justice expectations make any intervention prohibitively costly but do not increase the subsidiary managers' (already high) ex ante motivations, thereby leading the HQ to forego an otherwise value-enhancing intervention. ["Forgone interventions"]

- 3B: When goal conflict is high $\left(\pi_{M N C}^{G S}-\pi_{M N C}^{L A}>g\right)$ and the cost of fair procedure is low ( $\left.g<b_{S}\right)$, high procedural justice expectations lead the HQ to expend unnecessary resources and time on procedural justice in order to intervene fairly, but this has no positive effect on the subsidiary managers' (already high) ex ante motivations. ["Unnecessary procedures"]

- 3C: When goal conflict is high $\left(\pi_{M N C}^{G S}-\pi_{M N C}^{L A}>b_{S}\right)$, the cost of fair procedure is high ( $g>b_{S}$ ), and the initiative is highly attractive $\pi_{S U B}^{G S}>b_{S}$, high procedural justice expectations do not change subsidiary managers' ex ante motivations (as they take on the initiative in any case) or the behavior of the HQ (which intervenes in an authoritarian way in any case), but they do lead to bad-citizen behavior that would not have occurred given low procedural justice expectations. ["Disgruntled subsidiary managers"].

- 3D: When goal conflict is high $\left(\pi_{M N C}^{G S}-\pi_{M N C}^{L A}>b_{S}\right)$, the cost of fair procedure is high ( $\left.g>b_{S}\right)$, and the initiative is moderately highly attractive $\left(\pi_{S U B}^{G S}-b_{S}<0<\pi_{S U B}^{G S}-\beta_{0}\right)$, high procedural justice expectations lead subsidiary managers to drop initiatives that they would otherwise have undertaken because they anticipate procedural justice expectations being violated by authoritarian intervention and their own ensuing bad-citizen behavior, which destroys the attractiveness of the initiative ["Forgone initiatives"].

\section{APPENDIX 3}

Substituting the expressions for the GS and LA strategies results in the profit functions $\pi_{S U B}^{L A}=1+a-c$, $\pi_{R O M}^{L A}=1-a-(1-a) h^{2}, \quad \pi_{S U B}^{G S}=1+a-\frac{1}{4}(1-a)^{2}(1+a) h^{2}-c, \quad$ and $\pi_{R O M}^{G S}=1-a-\frac{1}{4}(1-a)(1+a)^{2} h^{2}$

. MNC profits for each of the two strategies can then be calculated as $\pi_{M N C}^{L A}=2-(1-a) h^{2}-c \quad$ and $\pi_{M N C}^{G S}=2-\frac{1}{2}\left(1-a^{2}\right) h^{2}-c$ $\pi_{M N C}^{G S}-\pi_{M N C}^{L A}=\frac{1}{2}(1-a)^{2} h^{2}$ and goal conflict is given by constraints on the profit functions. Goal conflict is ensured because the subsidiary profits are highest when the LA strategy is pursued, and MNC profits are highest when the GS strategy is pursued. At the same 
time, MNC spillovers from the initiative are never negative- the worst case is when diversity is at its maximum $(h=1)$, in which case the LA initiative is worthless (but still not downright damaging) to the rest of the $\mathrm{MNC}$, i.e. $\pi_{R O M}^{L A}=1-a-(1-a) 1^{2}=0$. Also, we can see that goal conflict is increasing in country diversity, but decreasing in subsidiary importance, and that initiative attractiveness is increasing in subsidiary importance and decreasing in initiative cost, as we would expect. These explicit profit expressions can be substituted into the propositions developed in the paper, enabling us to derive a graphical expression for the effects of the parameters, as shown in the Figures 3-6. 